\title{
Major Climate Variability and Natural Factors in Boreal Winter
}

\author{
INDRANI ROY ${ }^{1}$ (D)
}

\begin{abstract}
The role of natural factors, mainly solar 11-year cyclic variability and volcanic eruptions on two major modes of climate variability the North Atlantic Oscillation (NAO) and El Niño Southern Oscillation (ENSO) are studied for about the last 150 years period. The NAO is the primary factor to regulate Central England Temperature (CET) during winter throughout the period, though NAO is impacted differently by other factors in various time periods. Solar variability during 1978-1997 indicates a strong positive in-phase connection with NAO, which is different in the period prior to that. Such connections were further explored by known existing mechanisms. Solar NAO lagged relationship is also shown not unequivocally maintained but sensitive to the chosen times of reference. It thus points towards the previously known mechanism/relationship related to the Sun and NAO. This study discussed the important roles played by ENSO on global temperature; while ENSO is influenced strongly by solar variability and volcanic eruptions in certain periods. A strong negative association between the Sun and ENSO is observed before the 1950s, which is positive though statistically insignificant during the second half of the twentieth century. The period 1978-1997, when two strong eruptions coincided with active years of strong solar cycles, the ENSO and volcano suggested a stronger association. That period showed warming in the central tropical Pacific while cooling in the North Atlantic with reference to various other anomaly periods. It indicates that the mean atmospheric state is important for understanding the connection between solar variability, the NAO and ENSO and associated mechanisms. It presents critical analyses to improve knowledge about major modes of variability and their roles in climate and reconciles various contradictory findings. It discusses the importance of detecting solar signal which needs to be robust too.
\end{abstract}

Keywords: Solar cyclic variability, NAO, ENSO, volcanic eruptions, multiple linear regression.

$\begin{array}{ll}\text { Abbreviations } \\ \text { AOD } & \text { Aerosol optical depth } \\ \text { CET } & \text { Central England Temperature } \\ \text { CMIP5 } & \text { Coupled Model Inter-comparison Project } 5\end{array}$

Electronic supplementary material The online version of this article (https://doi.org/10.1007/s00024-020-02522-z) contains supplementary material, which is available to authorized users.

1 IRDR, University College London (UCL), London, UK. E-mail: indrani.roy@ucl.ac.uk

$\begin{array}{ll}\text { ENSO } & \text { El Niño Southern Oscillation } \\ \text { EOF } & \text { Empirical Orthogonal Function } \\ \text { GCR } & \text { Galactic cosmic ray } \\ \text { NAO } & \text { North Atlantic Oscillation } \\ \text { NH } & \text { Northern hemisphere } \\ \text { RCP } & \text { Representative concentration pathway } \\ \text { SH } & \text { Southern hemisphere } \\ \text { SSN } & \text { Sunspot number } \\ \text { SST } & \text { Sea surface temperature } \\ \text { SLP } & \text { Sea level pressure } \\ \text { UV } & \text { Ultra violet }\end{array}$

\section{Introduction}

The Sun is the main source of energy of the earth, but the level of scientific understanding relating to its influences on climate is still low (IPCC 2013). Regarding energy output, there is only a $0.1 \%$ change between maximum to minimum of the solar 11-year cycle (Lean and Rind 2001), which is too negligible to influence climate. However, studies identified significant regional impacts which are felt seasonally (Gray et al. 2010; Roy and Haigh 2010; van Loon et al. 2007) and sometimes depend on the overall period chosen (Roy and Haigh 2012; Roy 2014). In understanding climate variability and in interpreting signals of climate change, it is important to ascertain the actual role of natural factors, so that any human influence may be more accurately identified. More caution is also required to detect signals relating to natural variability (mainly the Sun) and the robustness of identified signature need to be tested from a critical viewpoint.

Nowadays, there is general agreement that the direct effect of the changes in the ultraviolet (UV) 
part of the spectrum (6-8\% between maxima and minima years of the 11-year cycle) leads to more ozone and warming in the upper stratosphere in solar maxima (Gray et al. 2010). The variation of ozone, through absorption of solar UV spectrum around the upper stratosphere, is one responsible factor for controlling temperature gradient between summer and winter hemisphere. Subsequently, through the well-known thermal wind balance variability, the solar cycle can regulate the strength of polar vortex, suggesting a stronger stratospheric polar jet in active solar years and vice versa. Baldwin and Dunkerton (2001) showed perturbation in the polar vortex can affect the polar troposphere during the same season. Kodera and Kuroda (2002) proposed a mechanism, whereby active solar years have the potential to influence the polar vortex and subsequently down to the lower tropical stratosphere, which also involves upward propagating planetary waves. The solar signal from the lower tropical stratosphere was shown to impact troposphere by modulating Hadley circulation and Ferrel cell (Haigh 1996; Haigh et al. 2005). All these mechanisms, by which, solar variability that affects the stratosphere are transported downwards and subsequently influences tropospheric climate is known as solar 'Top-Down' mechanism. Solar 'Bottom-Up mechanisms are also proposed (Meehl et al. 2008, 2009) those involve Sea Surface Temperature (SST) of the Pacific Ocean to influence tropospheric climate. In tropospheric climate, global temperature is an important atmospheric variable which was investigated by Lockwood and Froehlich (2007) in terms of solar variability. They concluded that the rise in global temperature since the last two decades of the twentieth century correlates poorly with solar variability although it suggests to the contrary during periods prior to that.

Ineson et al. (2011) analysed the regional impact of the solar 11-year cycle on North Atlantic Oscillation (NAO) (the dominant mode of climate variability during boreal winter around the North Atlantic) by using UK Met Office Unified Model and found an in-phase relationship. They imposed a vast change in solar UV irradiance to produce their observed response. According to them, in years of low (high) UV activity, easterly (westerly) winds and cold (warm) winters are favoured to northern Europe indicating a negative (positive) NAO pattern. It is interesting to study the robustness of such a proposed association between the Sun and NAO (Ineson et al. 2011). One of the focuses of the current study is to explore that area using observational data. Modelling work of Sjolte et al. (2018) discussed that the solar NAO link is not unequivocally supported by reconstructions. Apart from zero lag case, recent studies also explored the connection between solar 11-year cycle and winter NAO on various lag scales. Those include observational (Gray et al. 2013) as well as Modelling works (Andrews et al. 2015; Thieblemont et al. 2015; Scaife et al. 2013). The current study will also investigate the robustness of such association.

Apart from variations in the Sun, another major natural variability is volcanic eruptions (discussed in detail by Robock 2003). The radiative effect of a volcano is global cooling irrespective of the period considered, but its actual influence around continents of the Northern Hemisphere $(\mathrm{NH})$ suggests winter warming (Robock and Mao 1992) and needs attention. Using reanalysis data of the twentieth Century version 2 (20CRv2), (Compo et al. 2011), a significant surface warming over northern Europe and Asia was detected by Driscoll et al. (2012). Results from Coupled Model Inter-comparison Project 5 (CMIP5) simulations (Driscoll et al. 2012), concluded that the models fail to capture the $\mathrm{NH}$ dynamical response following eruptions. The effect of volcanos on NAO was also investigated (Sjolte et al. 2018) which indicated a positive NAO pattern during the following winter. However, they showed past major explosive eruptions had more lasting effects during the instrumental era. More studies are required to explore the connection/mechanism relating to volcano and NAO.

Volcanic aerosols also have the potential to change stratospheric chemistry with most necessary chemical changes in the stratosphere related to ozone (Robock 2003). After 1991 Pinatubo eruption, ozone column reduction of about 5\% was noticed in between mid-latitudes of both the $\mathrm{NH}$ and Southern Hemisphere (SH). Considering ozone depletion in the aerosol cloud, it was much larger (20\%). Thus, if intense volcano and atmospheric dynamics come together with the right timing, they could reinforce one another with different drastic results. During 
1978-1997, the two strong eruptions (El Chichón and Pinatubo) coincided with the near peak years of very active solar cycles. Knowing that the ozone in the stratosphere is modulated by solar cycles and explosive volcanos, it is interesting to study the role of the last two eruptions, considering the phases of solar cycles. This study shows that separating the period '1978-1997' is important to better understand some climate features. This was pointed out earlier (Roy 2016 [version 1, version 2]) and is supported by recent studies (Polvani et al. 2017; Oliva et al. 2017).

El Niño Southern Oscillation (ENSO) is a major climate phenomenon of the atmosphere and ocean and through different teleconnections, affects almost all parts of the globe. Various ENSO index time series is formulated, based on slightly different geographical considerations of tropical Pacific SST. The most widely used one is the Niño 3.4 Index, which has geographic coverage of $\left(5^{\circ} \mathrm{N}-5^{\circ} \mathrm{S}, 170^{\circ} \mathrm{W}-120^{\circ}\right.$ W) and is used in this study.

Growing body of evidence suggests the low-frequency variability of ENSO is primarily modulated by decadal variability originated in the North Pacific (Gu and Philander 1997; Latif et al. 1997). The decadal mode of ENSO might be related to solar 11-year cycle. Applying Empirical Orthogonal Function (EOF) technique on SST, White et al. (1997, in their Fig. 6, Top) using data from the latter period of the twentieth century showed that tropical Pacific SSTs resemble positive phase of the ENSO and is also in phase with the 11-year solar cycle. Using the Method of Solar Maximum Compositing, van Loon et al. (2007), and Meehl et al. (2008) detected an enormous negative signature in tropical Pacific SST for 150 years period, similar to that of the negative phase of ENSO. However, using the same dataset, over a similar time period, Roy and Haigh (2010) could not detect negative solar signal around tropical Pacific using Regression Technique. Haam and Tung (2012), Roy and Haigh (2010, 2012) and Roy $(2010,2014)$ addressed those contradictory findings in detail and reconciled some of the contradictions and discussed few mechanisms. Studies still suggest that solar-ENSO behaviour is a major area of dispute in climate science. More critical analyses and thorough investigations are vital to understanding the exact nature of those connections and its implication to global-scale climate responses.

Emily-Geay et al. (2008) showed, regardless of solar forcing, explosive volcanos with a radiative forcing greater than $3.3-4 \mathrm{Wm}^{-2}$ (roughly the magnitude of the El Chichón and Pinatubo eruptions), noticeably influence the modelled ENSO. Those can even significantly raise the likelihood of an El Niño event above the model's internal variability level. The response of ENSO from explosive volcanism was studied by Adams et al. (2003) by using two different paleoclimate reconstructions and two independent, proxy-based chronologies from AD 1649. They found a significant, multi-year, El Niño-like response over the past several centuries and nearly twice the probability of an El Niño occurrence in the winter following a volcano. Ohba et al. (2013) also studied the effect of massive eruptions in the Model for Interdisciplinary Research on Climate (MIROC5). It suggested about excitation of the anomalous west Pacific westerly which subsequently causes an increase in the probability of El Niño that agrees with observational data of longer-term paleoclimate records (Adams et al. 2003; McGregor and Timmermann 2011). A similar response is also noticed by Stenchikov et al. (2009) that used the Geophysical Fluid Dynamics Laboratory (GFDL) CM2.1 model. The model result of Ohba et al. (2013) suggests that explosive volcanos during El Niño phase contribute to the duration of El Niño, whereas the same during La Niña counteract to its duration, shortening its period. Using targeted climate model simulations, Khodri et al. (2017) further explored the effect of Pinatubo-like strong eruptions and showed those indeed favour an El Niño-like response. The effect of strong volcanos on El Niño is more substantial than that in La Niña due to the amplification by the air-sea coupled feedback (Stenchikov et al. 2009; Khodri et al. 2017). All these indicate studies relating to the effect of explosive volcanism on ENSO needs further exploration.

The ENSO plays a key role in regulating global temperature. The warming of the tropical Pacific from 1990 to mid-1995 was unprecedented in the observational record for more than a century (Trenberth and Hore 1996). Wang and Fiedler (2006) discussed that there was a failure to recognize the 
1982-1983 El Niño (the strongest one over a hundred-year period) until it was well developed. They also discussed the unusual nature of warm events of ENSO during 1990-1995 in the context of an observed trend for fewer La Niña and more El Niño after the late 1970s. The mean SO index for the post1976 period is statistically different $(<0.05 \%)$ from the overall mean and it is also true for the period 1990-mid-1995 (Trenberth and Hoar 1997). There is a good correspondence between the ENSO and temperature of the troposphere (Sobel et al. 2002), with warm periods coincide with El Niño's whereas, the cold with La Niña's. At the warm phase of ENSO, the troposphere is capable of carrying more water vapour. In a cloudless sky, water vapour is the most important greenhouse gas that constitutes $60 \%$ of total radiative forcing (Kiehl and Trenberth 1997). Ranked by their direct contribution, the largest greenhouse gas compounds are water vapour, and clouds (36-72\%) which have far higher contribution than that of $\mathrm{CO}_{2}(9-26 \%)^{1}$. Using satellite data, Laken et al. (2012) showed that ENSO is also the most accountable factor for changes in cloud cover. All these studies indicate that the role of water vapour and cloud, associated with the ENSO, has a vital role in regulating global temperature and needs attention.

Interestingly, the SST trend along the equator in the final 50 years of the twentieth century shows an El Niño-like pattern which is robust for all observations even using different datasets. However, there are controversies for the trend pattern of the longtime historical SST observations, as it differs substantially among datasets and time periods (Liu et al. 2005). Qiong et al. (2008) showed the standard deviation of Niño-3 SST increased to around $0.9-1.0{ }^{\circ} \mathrm{C}^{1}$ during the last two decades of the twentieth century and showed a nearly $50-60 \%$ rise in the ENSO variability (significant at the $95 \%$ confidence level). Though the decadal variation of the tropical climate has a considerable contribution to the ENSO variability (Fedorov and Philander 2000), the amplitude of the ENSO variability still suggested a robust, rising trend during that period, even removing that decadal contribution (Zhang et al. 2008).

\footnotetext{
${ }^{1}$ https://en.wikipedia.org/wiki/Greenhouse_gas.
}

Using observational data, this paper addresses many of these issues involving various modes of climate variability. It reconciles some of the contradictory findings and presents a critical viewpoint to advance our understanding relating to major modes of variability and their role in climate. It will help improve understanding of various climate modes and related teleconnections; which can subsequently lead to improved future prediction skill.

The structure of this study is as follows. Section 2 discusses the Methodology and Data. Results are detailed in Sect. 3 and have four sub-sections. The Sect. 3.1 covers analyses using time series of several factors. The first part discusses the general behaviour of different indices and their combined effect; while the second part focuses on the results of regression using various indices. Section 3.2 examines data to identify the spatial signature. Few questions on Sun NAO lagged relationship is raised in Sect. 3.3. Results are summarised in Sect. 4.

\section{Methodology and Data}

The method used here is the method of Multiple Linear Regression (MLR) analysis with AR (1) noise model. Noise coefficients are calculated simultaneously with the components of variability such as the residual matches with a red noise model order one. Following this methodology, it is possible to minimise noise being interpreted as a signal. The method is discussed in detail by Roy and Haigh (2010), Roy and Haigh (2010), Roy (2014, 2018a) and previously used by many other studies (Gray et al. 2010, 2013 among others).

Variables and climate indices used are Sea Level Pressure (SLP), SST, monthly Sun Spot Number (SSN), Niño3.4, Stratospheric Aerosol Optical Depth (AOD), (indicative of volcanic eruptions), longerterm linear trend (to represent anthropogenic influence), Central England Temperature (CET) and NAO. In the spatial plots of MLR analyses, SLP is the dependent parameter, while independent parameters are SSN, Niño3.4, AOD, and linear trend. For the solar signature (spatial patterns), zero lag case, as well as various lag situations, i.e., lag 1-3 (Gray et al. 2013), are also considered. For zero lag case, the 
MLR technique is also applied on CET, NAO and ENSO.

For SLP, the in-filled HadSLP2 dataset from Allan and Ansell (2006), that covers the whole globe and available as monthly means from 1850 to 2004 are used. It can also be found from https://www. metoffice.gov.uk/hadobs/hadslp2. Unlike HadSLP1, error estimates are mentioned for HadSLP2, to have ideas about regions of low confidence. Measurement and sampling errors are large in the high southern latitude due to the lesser number of observations, though it is small in other areas. The estimates lie between the observational error estimates of Kent and Taylor (1997) of $2.3 \pm 0.2 \mathrm{hPa}$ and those of Ingleby (2001) of $1 \mathrm{hPa}$ over most of the ocean basins. HadSLP2 data has been updated later upto 2012 using HadSLP2r_lowvar data (https://www.metoffice.gov. uk/hadobs/hadslp2/data/download.html). It is a version of HadSLP2r and consistent with HadSLP2. I have also extended the analyses for SLP upto 2012 using HadSLP2r_lowvar data (like Roy and Kripalani 2019), but the main findings did not change. In the current analysis for SLP, I discussed results only upto 2004, that solely used the HadSLP2 data.

For SST, NOAA extended SST v4 (ERSST) data is used (Liu et al. 2014), which is available from 1854 till date in a $2^{\circ} \times 2^{\circ}$ latitude and longitude grid. It is a revised version of ERSST v3b and much improved one. The data quality is more reliable and consistent after 1880 and we considered that period. It is available from NOAA, Boulder, from their Web site at https://www.esrl.noaa.gov/psd/ and also from https:// www.ncdc.noaa.gov/data-access/marineocean-data/ extended-reconstructed-sea-surface-temperatureersst-v4/. Quality of data and associated quantification of uncertainty is discussed in detail in the literature (Huang, et al. 2015). In this study, the global surface air temperature is also analysed, which is NOAA, Goddard Institute for Space Studies (GISS) Land and Ocean Temperature data from https://www.ncdc.noaa.gov/cag/global/timeseries. It is available from 1880 . Uncertainty quantification of this data is discussed in Lenssen et al. (2019). To verify the result with another global temperature data, Climate Research Unit (CRU) temperature records are consulted which is available since 1850. It can be downloaded from https://www.metoffice.gov.uk/hadobs/hadcrut4/data/ 4.4.0.0/time_series/HadCRUT.4.4.0.0.monthly_ns_ avg.txt. Sampling error, coverage uncertainty and other details are described in Morice et al (2012).

SSN is used to represent solar cyclic variability, which is available from https://www.sidc.be/silso/ versionarchive (version 1). The main advantage of using SSN is that it is free from the influence of trends and only captures the cyclic variability of the Sun. SSN is strongly correlated with various solar related parameters e.g., UV variability, visible solar irradiance and solar F10.7 [which is solar flux that can be measured in the ground and have bandwidth of $10.7 \mathrm{~cm} \mathrm{(2800} \mathrm{MHz)],} \mathrm{while} \mathrm{anti-correlated} \mathrm{with}$ Galactic Cosmic Ray (GCR) and hence can be considered as a proxy for all those indices. It is the most commonly used solar index for analysing long-term climate data. Moreover, the eleven-year cyclic nature of SSN can also be a very useful feature for future prediction purposes.

For ENSO, Niño 3.4 index, obtained from Kaplan et al. (1998) is used which is available since 1856 and can also be found at https://climexp.knmi.nl. In the regression, AOD has been employed to represent volcanic eruptions and available from https://data. giss.nasa.gov/modelforce/strataer/. It is also found from KNMI Climate Explorer (https://climexp.knmi. $\mathrm{nl})$. Longer term trend is a rising linear line that represents the increasing anthropogenic influence of the twentieth century. In this analysis, NAO index from Climate Research Unit (CRU), University of East Anglia is used which is accessible since 1823. It is developed by Jones et al. (1997) that considered instrumental pressure observations from Gibraltar and southwest Iceland and also available from https:// www.cru.uea.ac.uk/ timo/projpages/nao_update. $\mathrm{htm}$. The CET data is the longest instrumental record of temperature in the world and described in various publications (Manley 1974; Parker et al. 1992; Parker and Horton 2005). Being historic in Nature, the quality and reliability of this dataset is believed to be of high standard; though more reliable for the period of our analyses (since 1856). It is available since 1659 and can be downloaded from https://www. metoffice.gov.uk/hadobs/hadcet/data/download.html. 


\section{Results}

\subsection{Analyses Using Mainly Time Series of Various Factors}

\subsubsection{The General Behaviour of Different Indices and Their Combined Effect}

Figure 1 is the time series (DJF) plot of various parameters. Figure 1a shows global surface air temperature anomalies and Fig. 1b-e shows time series of various independent factors those are likely to influence that temperature. Figure $1 b$ is the time series of AOD; Fig. 1c, d are solar eleven-year cyclic variability (here SSN) and Niño3.4 index (representing ENSO), respectively. Figure 1e is the linear trend that represents longer-term climate change and mainly arises out of anthropogenic influence.

Due to a large specific heat of the ocean, it can retain heat for a longer time scale and thus the longterm variation of solar output is captured and detected mainly in the oceans. The Atlantic Multi-Decadal Oscillation (AMO) and Pacific Decadal Oscillation (PDO) are two primary modes of variability in the Northern Hemisphere $(\mathrm{NH})$ which are generated due to the atmosphere and ocean coupling and substantially can also modulate global temperature. In the current study, the primary interest, however, is on the role of climate variability on time scales of decades and less and thus, PDO and AMO, which have a longer-term variability of $\sim 20-30$ years are not included. Moreover, those modes are not considered as an independent variable, rather they are the regional manifestation of longer-term SST variability.

Here is a brief discussion on global surface air temperature variation as it corresponds to Fig. 1a. Three phases (I, II and III) are marked (Fig. 1) based on various combinations of the strength of volcanic activity and SSN that also follow the variation of temperature. Period (I) suggests a cooling in temperature (1880-1917); period (II) suggests a rise (1917-1944); whereas, period (III) shows an abrupt increase in temperature (1978-1997).

The Sun and the volcano: During the latter half of the twentieth century, the period dominated by the sudden rise in global temperature, the solar cycles are also seen to be stronger as noticed in Fig. 1c. In addition, three major volcanos erupted during 1963, 1982 and 1991 and the last two even coincided with the near peak of active solar cycles. Though massive volcanic eruptions occurred in solar peaks are a pure coincidence, but if it happens, it can change the mean state of stratosphere as well as troposphere. Subsequently, it may alter the strength and nature of solar so-called 'Top-Down' mechanism. Moreover, the ocean-atmosphere coupling system is also disturbed. Thus, both the direct (radiative) and indirect (dynamical) effects of the sun need to be considered to judge its contribution to surface climate.

The late 1800 s to the early 1900 s (period 'I') was a very active period of volcanic eruptions and those also coincided with minimum/near minimum years of solar 11-year cycles. Together with a quiet Sun (Fig. 1c), period ' $\mathrm{I}$ ' was cold as seen in Fig. 1a. While the period from 1917 to 1944 (marked by 'II') was a period of very little volcanic activity that coincided with an increase in solar irradiance. It experienced a rise in global temperature. However, the primary focus here is the last two decades of the twentieth century, when there is a steep rise in global temperature (Fig. 1a, period III) and its relevance to natural variability. There was an abrupt increase in temperature during 1978-1997 (IPCC 2013). It coincidentally happened when two very active volcanos erupted during the near peak of active solar cycles.

To address more on global temperature variation under different combinations of volcano and Sun, I also analysed CRU global temperature data (Fig. S1). The results remain the same adding the confidence to our observation. Three periods (1860-1880, 1917-1944, 1978-1997) are marked with three coloured demarcating lines (black, blue and red respectively), when a rising trend of global temperature is noticed. Due to the availability of additional data of past periods in CRU, it is also possible to compare the period '1860-1880' with '1917-1944' in Fig. S1a-c. Both the periods noted a rise in global temperature, absence of major volcanic activity and small to moderate solar cycles. For ENSO, we did not notice many changes and hence not included in Fig.S1. 
(a) Surface Temperature

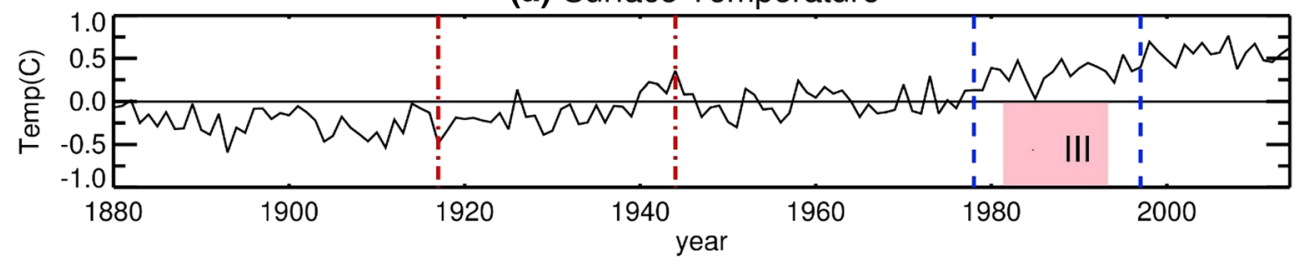

(b) Volcano

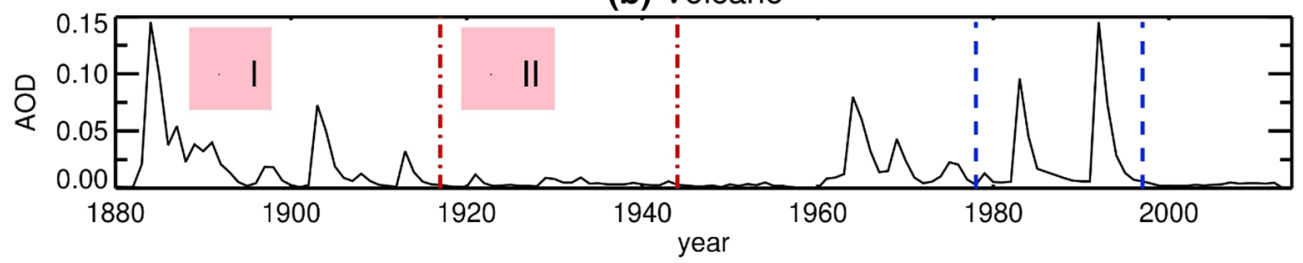

(c) Sunspot Number

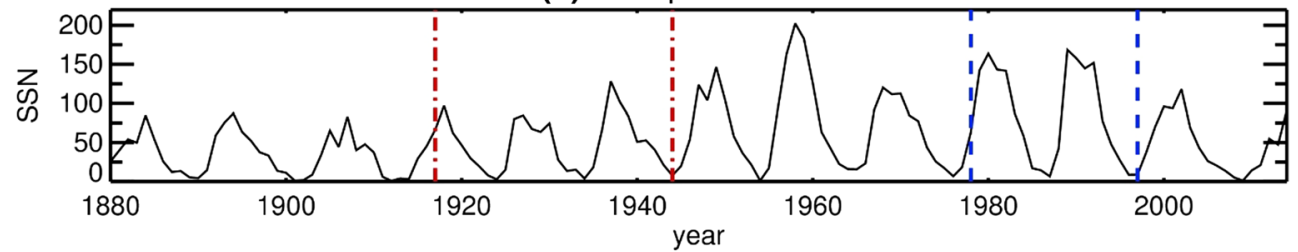

(d) ENSO

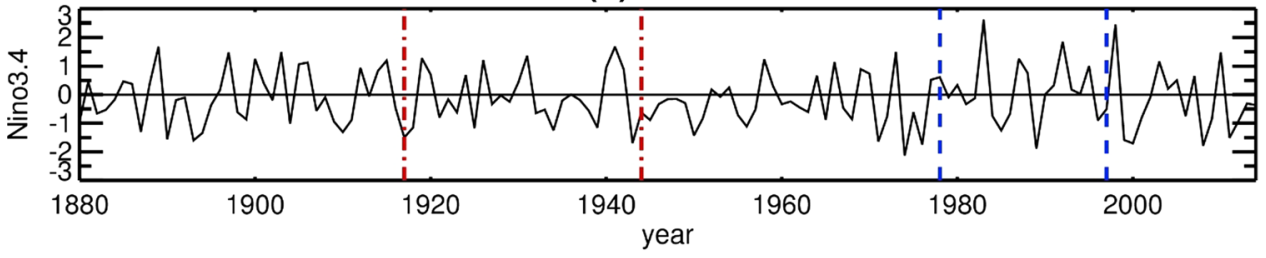

(e) Linear Trend

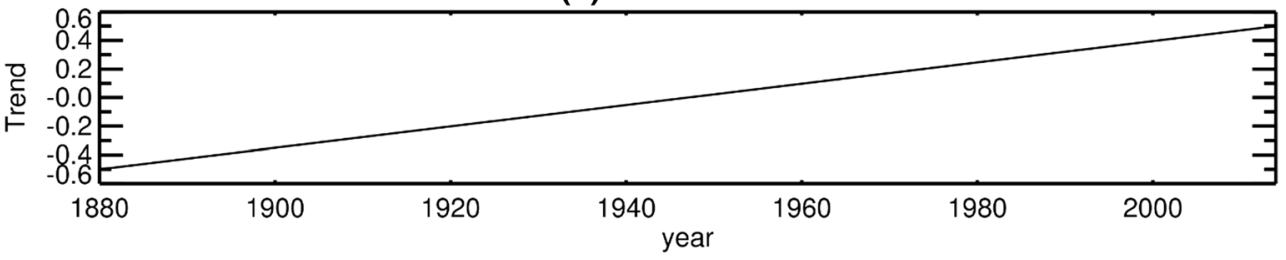

Figure 1

Time series of various independent parameters (b-e), those affect global surface air temperature (a). a Global surface air temperature anomalies (DJF), which is GISS Land Ocean temperature data, available since 1880. b-e Time series (DJF) of Stratospheric Aerosol Optical Depth (AOD) (b), Sunspot number (SSN) (c), ENSO, represented by Niño3.4 Index $\left({ }^{\circ} \mathrm{C}\right)(\mathbf{d})$, and normalised linear trend (e). Three periods (I, II and III) are marked based on various combinations of strength of volcanic activity and solar irradiance: (I) cooling of temperature (1880-1917); (II) rise in (1917-1944, marked by red boundaries) and (III) abrupt rise in temperature (1978-1997, marked by blue boundaries)

We speculate that not only the strength of eruption and the power of solar cycle necessary but also their combined behaviour that includes the timing of eruption relating to the phase of solar cycle are important in regulating the climate. It is interesting to investigate the role played by major variability (the Sun and volcano) individually and in combination, considering the dynamical and radiative influences with attention.

The role of ENSO: Figure 1d shows the time series of ENSO, which has an inter-annual variability of 2-7 years. It is usually of 2-3 years cycle during 
the overall analyses, apart from the latter period of the twentieth century when it even reached 5-7 years cycle. Period III is also seen dominated by warm events of ENSO. Thus, ENSO showed some differences in period III and discussed below.

Using 5 months running mean of Niño3.4 SST index, to represent ENSO, Trenberth and Hoar (1997, in their Fig. 1) clearly identified the highest ENSO signal during 1982 and that with the longest duration during 1992. They mentioned that from March 1991 to March 1995, the average ENSO did not change sign suggesting those peaks were clearly linked. Those features of ENSO in 1982 and 1991 are also evident in this work in Fig. 1d. Last two decades of twentieth century, experienced nearly 50-60\% increase in the ENSO variability (Qiong et al. 2008). Figure 1d agrees with such observations and supports Adam et al. (2003) and Ohba et al. (2013), that indicates volcanic forcing drives the coupled ocean-atmosphere system more subtly towards a preferential direction, where multi-year El Niño-like situations are favoured, which is subsequently followed by a weaker rebound into a La Niña-like condition. Now the number of El Niño outnumbers to that of La Niña during 1978-1997 with a significant rise of its variability and duration (Qiong et al. 2008; Trenberth and Hore 1996). It thus explains why SST trend along the equator in the final 50 years of the twentieth century shows a robust El Niño-like pattern for all observations using different datasets (Liu et al. 2005).

Water vapour is the most important greenhouse gas that constitutes $60 \%$ of total radiative forcing (Kiehl and Trenberth 1997). Moreover, note that there are fewer La Niña and more El Niño events after the late 1970s (period III). Thus, the rise in global temperature during that period and the different behaviour of El Niño that includes increase in amplitudes and time period (Trenberth and Hoar 1997; Trenberth and Hore 1996; Wang and Fiedler 2006) could be one interesting area which needs to be revisited.

The overall analyses indicate it is important to study the combined effect of ENSO, volcanic eruptions, and solar variability. In addition to their individual influences, such combination is vital to understand the overall climate impact regionally as well as globally.

Figure 2 shows the anomaly of SST during 1978-1997 (where two explosive volcanos erupted in active solar phases) to that from two different periods 1920-1940 and 1999-2017, respectively (when there are no massive volcanos). Those two anomaly periods (1920-1940, 1999-2017) are arbitrarily chosen and a slight change of years does not make any difference to the main result. Surprisingly an El Niño like pattern is noticed in both plots where central tropical Pacific SST has risen by around 0.4-0.8 ${ }^{\circ} \mathrm{C}$ during $1978-1997$. On the contrary, over the same period, there is a cooling around North Atlantic where SST cooled even more than $1{ }^{\circ} \mathrm{C}$. It is interesting to note the uniformity despite two different reference periods (one is even the very recent time). A similar detailed analysis is also carried by the author in recent research (Roy 2018b). In spite of the presence of well-discussed longer-term global warming trend throughout the period, central tropical Pacific and North Atlantic showed deviations. Considering various arbitrary reference periods (Fig. S2), similarly signed signals are still noticed during 1978-1997, which is warm in the central tropical Pacific, but cold in the North Atlantic. This period (1978-1997) only differs from rest other reference periods regarding explosive volcanos matching with high years of active solar cycles. Hence in subsequent analyses we focus on those two regions and focus on ENSO and NAO, considering solar variability and volcanos.

\subsubsection{Results of Regression Using Various Indices}

This section presents discussion based on MLR technique. MLR technique is applied to three different parameters CET, NAO and ENSO in three subsequent columns (1,2 and 3) and presented in Table 1. The first column (1) shows the value of regression coefficients using CET as the dependent parameter, with the independent factors as the NAO, SSN, AOD, ENSO, and trend. The second column (2) is the result due to SSN, AOD, ENSO and trend as independent parameters with NAO being the dependent factor. Whereas, the third column (3) calculates regression coefficients for ENSO as the dependent 
(a)

NOAA Extender SST V4 (ERS5T)

Surface SST (C) Composite Anomaly 1981-2010 climo
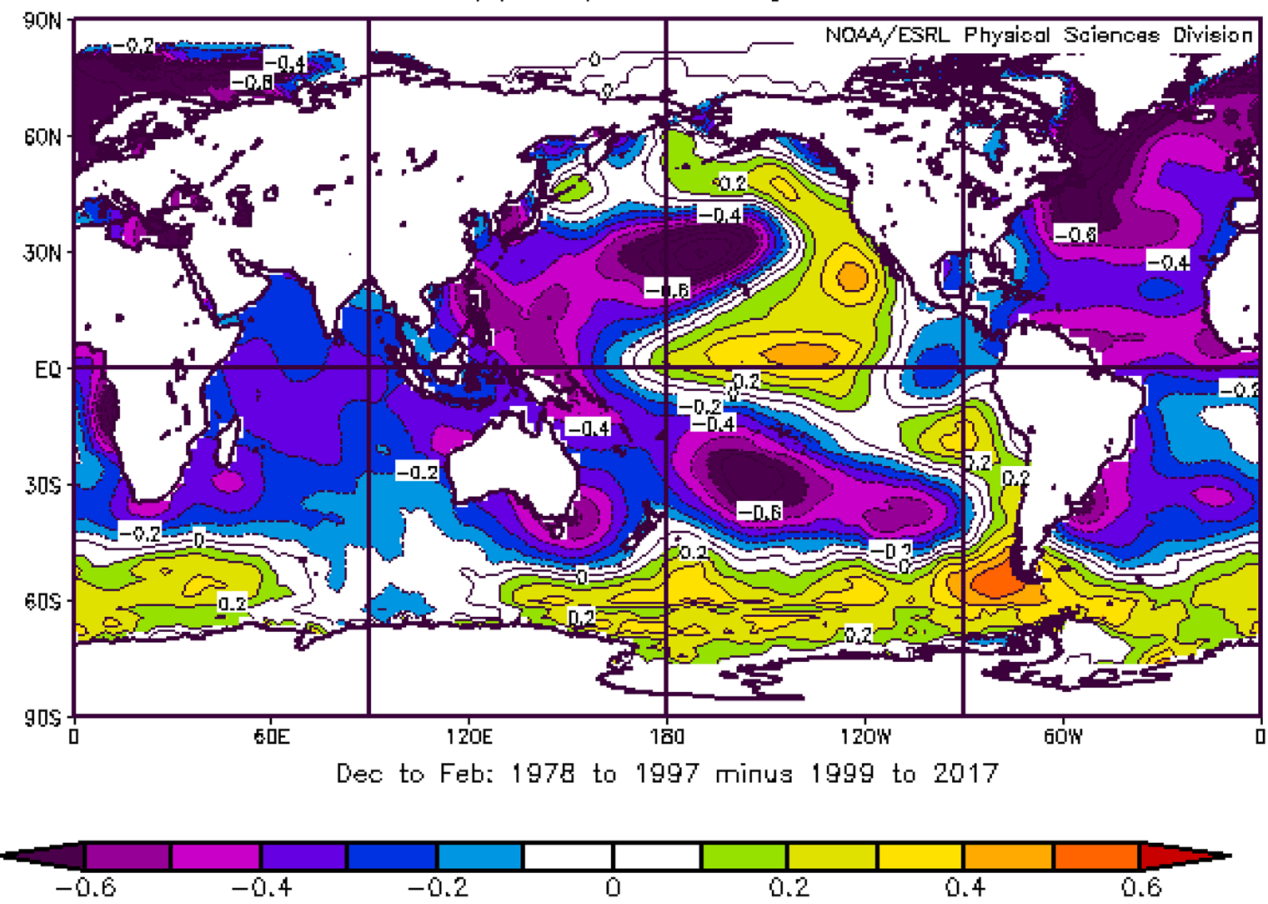

(b)

NOAA Extended SST V4 (ERSST)

Surface SST (C) Composite Anomaly 1981-2010 climo
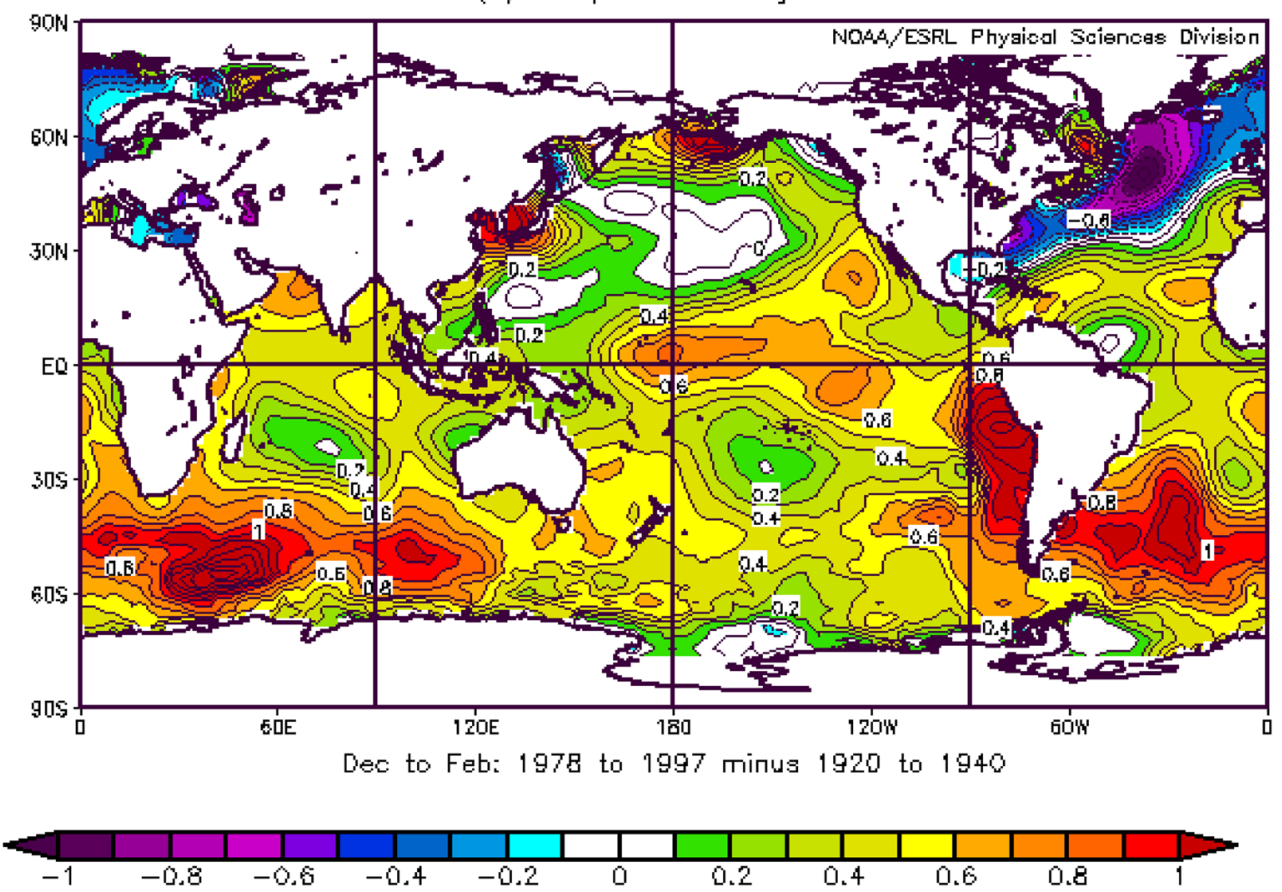

Figure 2

SST anomaly (DJF, in ${ }^{\circ}$ C) from NOAA Extended SST V4 (ERSST), top (a) for 1978-1997 minus 1999-2017, and bottom (b) 1978-1997 minus 1920-1940. Positive anomalies are shown by green, yellow and red colours and negative by blue. Zero contours are also labelled. SST anomaly higher than $0.5{ }^{\circ} \mathrm{C}$ are usually significant at $95 \%$ level 
Table 1

Regression coefficients for various indices during DJF in different time periods

\begin{tabular}{|c|c|c|c|c|}
\hline & \multirow{2}{*}{$\begin{array}{l}\text { Independent } \\
\text { parameters }\end{array}$} & \multicolumn{3}{|c|}{ Dependent parameters } \\
\hline & & (1) $\mathrm{CET}$ & (2) NAO & (3) ENSO \\
\hline $\begin{array}{l}\text { Period A } \\
\quad(1856-1997)\end{array}$ & $\begin{array}{l}\text { Trend } \\
\text { AOD } \\
\text { SSN } \\
\text { ENSO } \\
\text { NAO }\end{array}$ & $\begin{aligned} & 0.76 \\
- & 0.46 \\
- & 0.28 \\
& 0.06 \\
& 4.57 * * *\end{aligned}$ & $\begin{array}{r}-0.67 \\
1.18^{*} \\
0.39 \\
-0.17\end{array}$ & $\begin{array}{l}0.14 \\
1.07^{* *} \\
-0.20\end{array}$ \\
\hline $\begin{array}{l}\text { Period B } \\
\quad(1856-1957)\end{array}$ & $\begin{array}{l}\text { Trend } \\
\text { AOD } \\
\text { SSN } \\
\text { ENSO } \\
\text { NAO }\end{array}$ & $\begin{aligned} & 0.31 \\
- & 0.39 \\
- & 0.12 \\
& 0.22 \\
& 4.7 * * *\end{aligned}$ & $\begin{array}{r}-0.11 \\
0.86 \\
-0.04 \\
-0.11\end{array}$ & $\begin{array}{c}0.13 \\
0.15 \\
-0.84 * *\end{array}$ \\
\hline $\begin{array}{l}\text { Period C } \\
\quad(1958-1997)\end{array}$ & $\begin{array}{l}\text { Trend } \\
\text { AOD } \\
\text { SSN } \\
\text { ENSO } \\
\text { NAO }\end{array}$ & $\begin{aligned}- & 0.05 \\
- & 0.38 \\
- & 0.34 \\
- & 0.27 \\
& 4.01 * * *\end{aligned}$ & $\begin{array}{l}1.12 \\
1.07 \\
1.03 \\
0.28\end{array}$ & $\begin{aligned}- & 0.24 \\
& 2.01^{* *} \\
& 0.62\end{aligned}$ \\
\hline $\begin{array}{l}\text { Period D } \\
\quad(1978-1997)\end{array}$ & $\begin{array}{l}\text { Trend } \\
\text { AOD } \\
\text { SSN } \\
\text { ENSO } \\
\text { NAO }\end{array}$ & $\begin{aligned} & 1.04 * \\
- & 1.50^{* *} \\
& 0.15 \\
- & 0.02 \\
& 3.93^{* * *}\end{aligned}$ & $\begin{array}{l}1.74 \\
1.29 \\
1.70^{*} \\
0.52\end{array}$ & $\begin{aligned}- & 0.57 \\
& 2.18^{* * *} \\
- & 0.13\end{aligned}$ \\
\hline
\end{tabular}

Values significant at $90 \%, 95 \%$ and $99 \%$ level derived using a Student t-test are shown by $*, * *$ and $* * *$, respectively

variable with SSN, AOD, and trend as independent factors. In Table 1, I also considered different time periods for various reasons as follows:

Period '1958-1997': The period from the 1950s1997s was identified by several authors (e.g. Vecchi and Soden 2007) as the period of a weakening of both the Walker and Hadley circulations; more in the Walker than the Hadley circulation. On the other hand, over the same time, the shallow ocean Meridional Overturning Circulation in the Tropical Pacific was also weakened (Zhang and McPhaden 2006), suggesting that both the atmosphere and the ocean system was in an anomalous state. Hence, I separated that period (1958-1997) from (1856-1997) to find the influence of various factors.

Period '1978-1997': Numerous studies indicated the year 1976/1977 as climatic 'regime shift' (Miller et al. 1994; Meehl and Teng 2014) because many physical conditions in the atmosphere and ocean including global temperature changed abruptly during that period. Scafetta (2013) proposed that it could be due to a constructive interference among a number of natural oscillations. Substantial evidence also supports the idea that physical conditions changed around atmosphere (Minobe 2000; Bond et al. 2003) and ocean (McPhaden and Zhang 2004; Vecchi and Soden 2007) during 1998. Moreover, the last two very active volcanos erupted during that intervening period (1978-1997) coinciding the active phase of strong solar cycles. Hence, those two decades are also separated.

In Table 1, period ' $A$ ' is for the entire period of consideration up to 1997 which is (1856-1997); whereas, ' $\mathrm{B}$ ' only considers the time before 1957 ; ' $\mathrm{C}$ ' is after 1958, while period ' $D$ ' focuses the time 1978-1997. There could be issues related to lesser data points for the period ' $\mathrm{D}$ '; hence we also repeated the analysis of period D up to 2004 covering 26 years period- but the main findings did not change. In addition to that, results for period ' $\mathrm{A}$ ' and ' $\mathrm{C}$ ' were also extended upto 2004 (not shown here, as main findings remain the same). The primary purpose of depicting Table 1 is to show that period D (1978-1997) is different from the rest other periods under consideration. Hence results only upto end period of 1997 is presented. Results of significance in different degrees $(90 \%, 95 \%$, and $99 \%$ ) are marked by various symbols $(*, * *$ and $* * *$ respectively). However, major results are based only on significant levels of $95 \%$ and $99 \%$.

Influence on CET (column 1): In column ' 1 ' of Table 1, it is clearly seen that the NAO explains most of the variance for CET and the result is $99 \%$ significant in all the periods (A-D). Interestingly, during period D, volcano suggests cooling $(95 \%$ significant) in central England, while linear trend indicates warming (90\% significant). Irrespective of time periods considered, NAO plays a dominant role in regulating the temperature of England. Though the influence of NAO on CET is robust, NAO is seen to be influenced by other independent factors differently during different periods considered. Time series plot of NAO and CET in also presented in Fig. S1d, e.

Influence on NAO (column 2): Identifying the importance of NAO in controlling the temperature of Europe, Central England being one of the representative regions, it is now interesting to identify how 
NAO can be influenced by other factors and shown in column 2. Studies suggested that there are preferences of positive phases of NAO in climate change scenarios (Visbeck et al. 2001). This is consistent with the observation for trend during period $\mathrm{C}$ and $\mathrm{D}$, though only significant at $80 \%$ level. NAO and Volcanos show positive correlation throughout the period (A-D), but only significant at $90 \%$ level for period A. It is likely that the number of total occurrence of volcanos in period A might have a role. The regression coefficient in period $\mathrm{D}(+1.29)$ is seen to be higher than that in period A $(+1.18)$, but because of lesser data points, it fails to indicate the significant result. Such positive connection between volcano and NAO is also noted by Gray et al. (2013, their Fig. 3) using MLR technique for over 150 years of observational data.

Now the focus is on solar NAO behaviour. During the post-1957 period, the relationship between SSN and NAO has strengthened. From column 2, Table 1, it is seen that the NAO is influenced positively by SSN during period D (level of significance 90\%) and C (only 80\%, hence not marked) and the nature of this signature is consistent with the recent study by Ineson et al. (2011). Considering the period of the latter half of twentieth century Roy $(2010,2014)$ also detected such signal in observation. A recent work of Roy and Kriplani (2019, their Fig. 2c) considered SLP data of '1971-2012' that covered a total of 42 years data from recent period. It also showed a clear positive NAO pattern for the solar signature in zero lag case. Interestingly, when the focus is on period A and $\mathrm{B}$, the NAO solar relationship not only weakened but sometimes reversed in sign. Gray et al (2013, their Figs. 3 and 4) using data from longer time found a reverse association between the Sun and NAO. Furthermore, Roy and Haigh (2010, their Fig. 1) also detected similar features for a longer time period. In both those studies, Sun and NAO suggested a negative (insignificant) association matching to that of Period B. Such opposing nature of Sun and NAO during different periods though was shown in various popular papers but did not receive attention. This analysis thus questions robustness of the study of Ineson et al. (2011), which suggested that inactive phase of the Sun (as represented by solar UV variability in their model) is linked with the negative phase of NAO and vice versa. This work indicates the robustness of such association requires further exploration. The mean atmospheric state also needs to be taken into account with additional care in detecting the role of the Sun on major climate variability and proposing a mechanism based on any detected signals.

In Table 1, ENSO, however, does not show any significant influence on NAO in any of the periods.

Influence of ENSO (column 3): It is interesting to identify whether ENSO, i.e. the source of the dominant variability in tropics, is also influenced by other dominant factors. Possible candidates considered are longer-term trend, to represent a linear rise in temperature associated with anthropogenic influence, and natural variability represented by volcanic eruptions and SSN. The discussion mainly follows about ENSO and natural variability.

The results using ENSO as the dependent parameter (column 3) give one interesting finding relating to volcanic eruptions and ENSO. A volcanic eruption is seen to strongly favour positive phase of ENSO, but only true during the last half of the twentieth century. The signal is strongest (99\% significant) during period D (1978-1997), while weak in period B. Result during period B (1856-1957) is probably dominated by lesser/weaker volcanos during the first half of the twentieth century. Without many volcanic eruptions, ENSO still followed its own inter-annual variability. When considering the overall period of analysis in period ' $A$ ' (1856-1997), volcano and ENSO relationship is found to be dominated by period D and suggests a level of significance up to $95 \%$.

The period ' $\mathrm{D}$ ' is consistent with various works as discussed earlier (Emily-Geay et al. 2008; Ohba et al. 2013; McGregor and Timmermann 2011; Stenchikov et al. 2009; Adams et al. 2003; Khodri et al. 2017). Those studies discussed ENSO is noticeably influenced (in preference of its positive phase) by very strong explosive volcanic eruptions. It is also consistent with the observation of Fig. 1d and the fact that SST trend along the equator in the final 50 years of the twentieth century shows a robust El Niño-like pattern for all observations using different datasets (Liu et al. 2005). 
(a) (1856-1957)

Sun High $\stackrel{\text { Mechanism I }}{\longrightarrow} \begin{gathered}\text { ENSO Preference } \\ \text { (Cold) }\end{gathered} \stackrel{\text { Mechanism II }}{\longrightarrow}$ NAO negative

(b) $(1978-1997)$

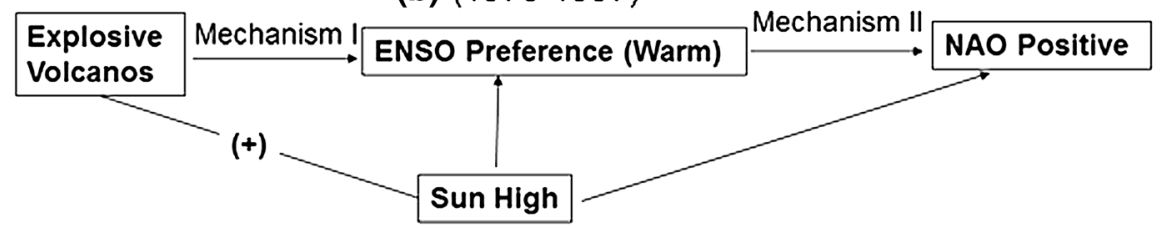

Mechanism I: Uniform Reduction of large solar radiation in tropical Pacific causes warm ENSO (Clement et al. 1996; McGregor et al. 2011)

Mechanism II: $\begin{aligned} & \text { Unusual warming in tropical Pacific favours positive NAO } \\ & \text { (Bjerknes } 1966 \text { ) }\end{aligned}$

Figure 3

Schematic describing the role of the Sun for around last 150 years period: a focuses an earlier period when the Sun and ENSO negative association was significant; for $\mathbf{b}$, the emphasis is on the period 1978-1997 and the role of explosive volcanos. More details on Mechanism I and II are discussed in the Supplementary text

A little discussion about the possible mechanism is added here (schematics are in Fig. 3). Warming in the central equatorial Pacific in response to explosive volcanos (Table 1, column 3) can be explained by a hypothesis known as the dynamical thermostat hypothesis (Clement et al. 1996). It states for a uniform reduction of incoming surface solar radiation to a large degree, (which is associated here with explosive volcanos) the response of SST is different on two sides of the tropical Pacific. Due to ocean advection theory, the western Pacific cools faster than the east. It initially reduces the climatological zonal SST gradient, which subsequently influences trade winds in the central Pacific. The resultant positive SST gradient can activate El Niño phase, reversing trade winds. McGregor and Timmermann (2011) proposed another theory that states, the anomalous westerly in tropical Pacific could be attributed to the rapid response over the maritime continent, in response to uniform reduction of incoming surface solar radiation (here due to volcano). It is mainly linked to the land-sea contrast, where the surface cooling around equatorial Pacific and its timescale for adjustment are leading responsible factor. It is the fast cooling around the maritime continent that contribute to the positive zonal SST gradient. It is noteworthy that the role of dynamical thermostat hypothesis (Clement et al. 1996) and the proposition of McGregor and Timmermann (2011) both can act together to reinforce the mechanism relating to volcano and ENSO.

Another interesting finding from column 3 is about solar-ENSO behaviour. In period $\mathrm{C}$ (1958-1997), there is a positive solar signal detected in ENSO, which is only significant up to $80 \%$ level. Though it is less significant, the sign of such signature agrees with White et al. (1997, their Fig. 6) who used data of second half of the twentieth century and detected a similar in-phase relationship between the Sun and ENSO. When the focus is on Period B (1856-1957), the relationship not only reversed, but even showed a significant result up to 95\% level. Interestingly Roy and Haigh (2012), focusing on a similar period of analysis, also observed the preferential alignment of the negative phase of ENSO in active phases of the solar cycle (i.e., when $\mathrm{SSN}>80$ ) during northern winter. Updating that record with current data (upto 2015) also confirmed such observation (Fig. 4). The recent four years of 2016-2019, being low solar years does 

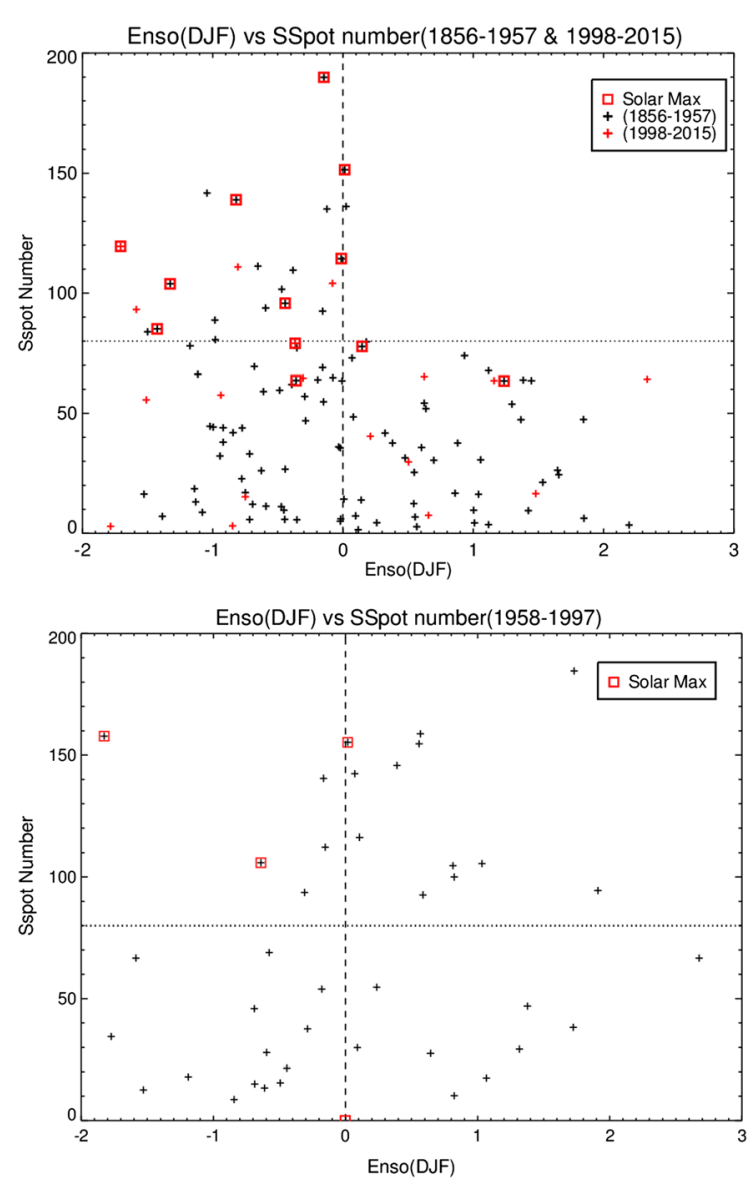

Figure 4

Scatter plot of ENSO (DJF) against annual average SSN from 1856 to 2015 inclusive. Red squares mark the peak years of solar cycles. All years during 1856-1957 and 1998-2015 are aligned to the negative phase of ENSO during active phases of the solar cycle (i.e., when SSN > 80), while intervening periods (1958-1997) show no such preferences for a high Sun

not make any difference to this result. Considering spatial pattern, Roy $(2010,2014)$ however could not identify a detectable signature in tropical Pacific Sea Surface Temperature (SST) using Hadley Sea Surface Temperature version 2 (HadSST2) data during the same period. This could be because that work considered every month of the year rather than only boreal winter. van Loon et al. (2007) and Meehl et al. (2008) using the method of a solar peak year compositing detected similarly signed (cold) signature during December January February (DJF), though it only focused on solar peak years rather than active/inactive phases of the solar cycle. Due to two opposite nature of signature in period $\mathrm{B}$ and $\mathrm{C}$, it is difficult to discern any solar-ENSO relationship for the entire period of analysis. That expected insignificant result is observed in period A.

During an earlier period (1856-1957, DJF), the significant negative association between the Sun and ENSO can also be explained by the hypothesis of a dynamical thermostat (Clement et al. 1996) and the proposition of McGregor and Timmermann (2011) (discussed in Fig. 3a). Interestingly, during the inactive phase of the Sun, there is a uniform reduction of surface heat fluxes and hence, the same principle as discussed for the volcano is equally applicable. It could trigger El Niño like situation, while active solar years will trigger La Niña like situation following the reverse mechanism. The decadal solar signature for inciting trade wind is clearly detected in Fig. 5a (left) (and discussed in Sect. 3.2), which is though small in magnitude (lower than $-1.5 \mathrm{hPa}$ ), but significant up to $95 \%$ level. Such an association is also seen in Table 1, Period B, column 3, as reflected by Sun ENSO connection $(\beta=-0.84$, significant at $95 \%$ level). In general, such analysis indicates that solar cycle drives the coupled ocean-atmosphere system more subtly towards a state in which La Niña conditions are usually favoured for active solar years; whereas, El Niño's for low solar years. At low solar years, the usual interannual variability of ENSO (governed by Kelvin and Rossby wave movement) dominates, but during high solar years, the solar signature overpowers as seen in Fig. 4 (top plot). In that plot, the ENSO suggested cold phase during peak solar years of active cycles $(\mathrm{SSN}>80)$. Even after the peak solar year, cold ENSO phase was also noticed after 1 to 2 years lag (Roy 2014; Roy and Haigh 2012). Overruling all speculations, the last solar peak year of 2014 again suggested the cold phase of ENSO. It is noteworthy that three other solar peak years from later decades of the last century (bottom plot, Fig. 4) which are not influenced by volcanos (year 1968, 1979, 1989) are also showing preference towards cold event side. Interestingly, the Sun ENSO connection was reverted again like earlier period since 1998 (Roy and Haigh, 2012, also seen in Fig. 4, top plot). 


\section{(a) Solar}
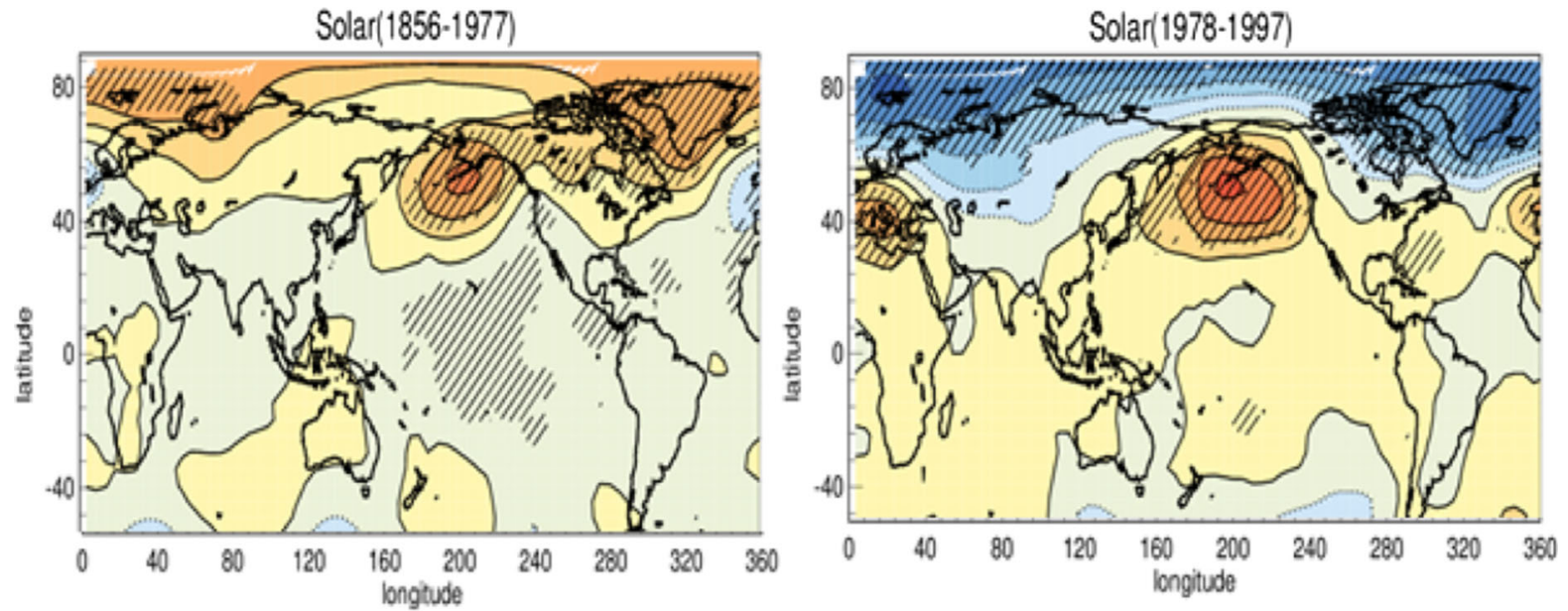

(b) ENSO

ENSO(1856-1977)

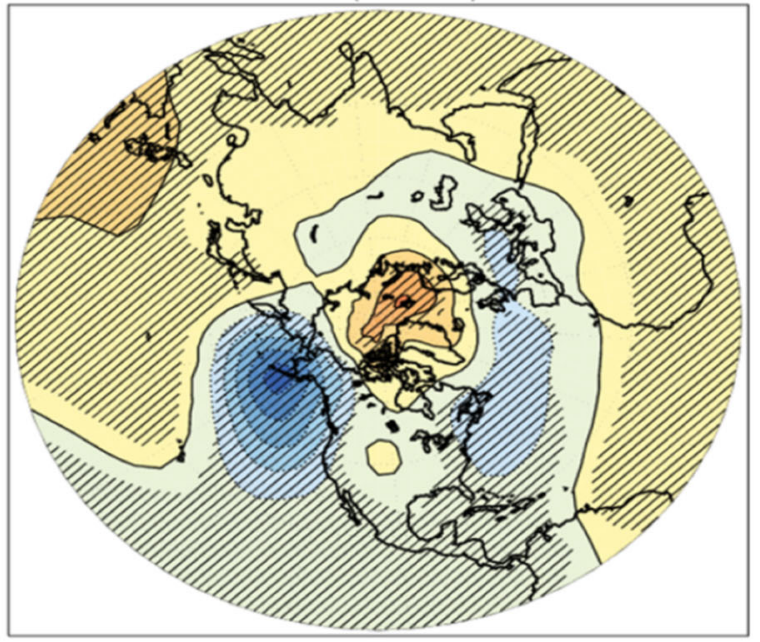

ENSO(1978-1997)

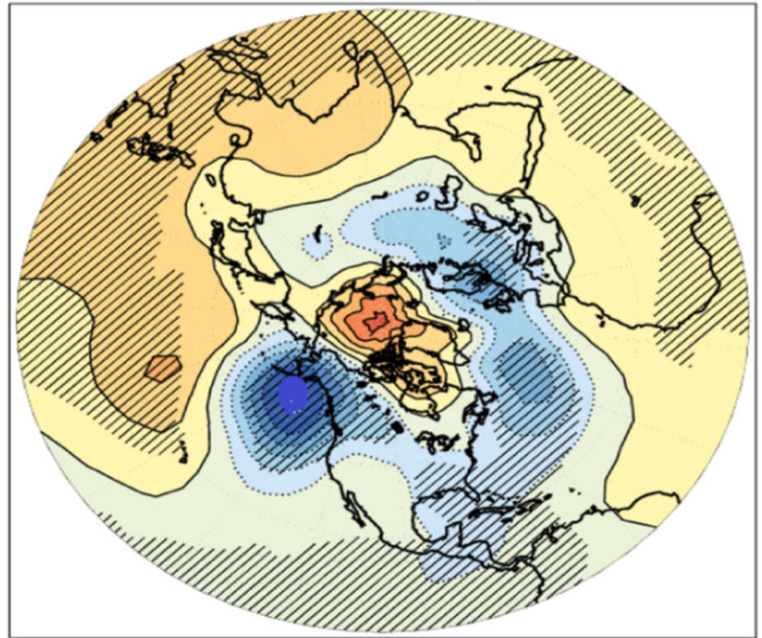

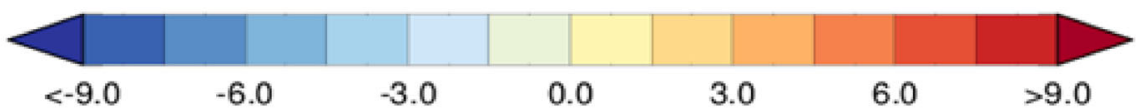

Figure 5

Amplitudes of the components of variability for SLP (in hPa) during DJF. The top panel (a) is due to SSN using different independent factors as longer term trend, AOD and ENSO; whereas, the bottom panel (b) is due to ENSO using independent factors as trend, AOD and SSN. The bottom panel is an equatorial stereographic map centered on the north pole, as it mainly focuses on the Arctic. The right panel is for period (1978-1997) and the left panel for (1856-1977). Positive values are shown in brown colour and negative by blue. Shaded regions are estimated significant at the $95 \%$ level using a t-test

\subsection{Spatial signatures}

Focusing attention on the spatial pattern, the MLR technique for zero lag case is applied to SLP with independent parameters as AOD, linear trend, ENSO, and SSN (Fig. 5). Shaded regions are estimated significant at the $95 \%$ level using a t-test. The major findings are discussed below. 
Signature due to the Sun: Fig. 5a shows the spatial pattern of solar signature in SLP. It excluded other major factors (volcano, ENSO, and trend), those are very likely to influence results. The right panel is for 1978-1997; whereas, left panel for the earlier period of available data series. In both the figures (Fig. 5a), a strong positive signal around Aleutian Low (AL) is clearly detected suggesting the robustness of that signal as also noticed by Roy and Haigh (2010). The right panel of Fig. 5a (and Fig. S3) suggests a positive Arctic Oscillation (AO) pattern; whereas, a clear dissimilarity is noticed around the far North Atlantic in the left panel. A positive NAO-like signature is distinguished in the right panel, in accordance with the results of Table 1 (Period D, column 2) and the study of Ineson et al. (2011). Surprisingly, that signature around the pole is reversed in the left panel (Fig. 5a) with significant region mainly localised around the places of Greenland. That reversal of signature is also noticed in Roy (2010, 2014), those used slightly different years; though neither discussed solar NAO connections, nor considered/compared various time periods over 150 years.

MLR is also performed with or without the inclusion of some of those chosen independent indices; however, the main results did not change. It supports the robustness of detected signals. Current analyses also explain why Roy and Haigh (2010, their Fig. 1) could not identify any NAO-like pattern using data of longer time period as is also seen and discussed in Table 1 (Period A, column 2). All such analyses raise doubt about the proposed relationship as discussed in Ineson et al. (2011) and other related studies based on similar mechanisms. It indicates that the robustness of solar NAO known connection needs exploring further.

A brief discussion is also presented on one possible mechanism relating to the Sun and NAO connection, which can be explained by the proposition of Bjerknes (1966). During later decades, the broader maxima of solar cycles (1-2 year after peak solar years) are inclined to warm events of ENSO (Roy and Haigh 2012; Roy 2014). Following Bjerknes (1966), (also discussed in detail in Fig. 3, Mechanism II), the anomalously great heat of warm equatorial ocean enters into the rising branch of the regional Hadley circulation and strengthens the cell. It generates above the normal flux of angular momentum to the westerly winds around midlatitude. Thus, warming in tropical Pacific can strengthen mid-latitude westerly jets during boreal winter and subsequently can favour a positive phase of NAO. Such response is strongest in the winter hemisphere due to greater baroclinicity. During the period (1856-1957, DJF), the Sun showed preferences towards La Niña phases (Roy and Haigh 2012; also, Table 1, Column 3, Period B) in all active solar years. Following similar mechanisms (Bjerknes 1966), it can suggest a weakening of mid-latitude westerlies in boreal winter, indicating a negative association between the Sun and NAO (Fig. 5a, left).

In Fig. 5a, apart from the north Atlantic, the solar signal around tropical Pacific is also seen to be different in the left panel to that from the right. In the left panel, the significant signal observed in the tropics (though small in amplitude but $95 \%$ significant) might be responsible to incite trade wind and thus can favour cold event like situations of ENSO via indirect dynamical coupling (Roy 2014). Such signature is missing in the right panel, which suggests it might be one factor that could also be responsible for different Sun and ENSO connection; positive during the 2 nd half of twentieth century though negative and significant in the earlier period (Table 1, Period B, column 3). The sign of respective signals around tropical Pacific and the north Atlantic remains similar for Fig. 5a (left), if the period is switched from '1856-1977' to '1856-1957'. It supports Mechanism I (Fig. 3) in connection with the Sun and ENSO, involving anomalous westerly in the tropical Pacific.

It is noteworthy that Roy (2018b) hypothesized a mechanism that is initiated in the mid-latitude and influences tropics and ENSO. Here I hypothesize that the tropical Pacific could also be a source of the initial trigger to the coupling mechanism between the tropics and mid-latitude. Interestingly, both the mechanisms, (either originated in the tropical Pacific or north Atlantic) reinforce each other and working in a similar direction to set the strong coupling between NAO, ENSO and the Sun during the latter two decades of the last century.

Different Sun ENSO behaviour (Fig. 4) during the later period (1958-1997) to that from earlier periods (1856-1957) reconciles some conflicting findings 
relating to the Sun, global temperature and ENSO (Lockwood and Froehlich 2007; Laken et al. 2012).

Signature due to the ENSO: Figure 5b shows the spatial signature of ENSO on SLP around the north polar region, excluding SSN, AOD, and linear trend. The right-hand panel is for 1978-1997 and left hand for 1856-1977. Both panels identify negative NAO pattern for ENSO around the pole. For solar signature (Fig. 5a), tropical Pacific trade wind was involved and hence the plot that covered tropical Pacific was shown. However, for ENSO signature in SLP, the focus of present discussion is mainly around polar regions of $\mathrm{NH}$ and hence a stereographic map centred on the north pole is presented (Fig. 5b). The positive phase of ENSO is responsible for the warming of polar vortex during northern winter, as detected in observation (Thompson et al. 2002) and model (Toniazzo and Scaife 2006). It subsequently suggests a negative phase of polar annular modes in the troposphere (Baldwin and Dunkerton 2001). One possible route how the ENSO influences polar vortex and then down to Arctic region can be through wellknown Brewer-Dobson circulation. There is another mechanism explaining the influence of ENSO on the polar vortex, through planetary waves. During the warm phase of ENSO more planetary waves are generated and interact with polar vortex. Significant signature is noticed around the Arctic in Fig. 5b leftpanel, but the variability of SLP is increased in the right panel (not significant). Lesser number of data points during the later period might be one cause for the reduced significance level. The increased amplitude of signals around the Arctic, however, could be linked to the fact that ENSO variability has increased (Fig. 1d) and unevenly high number of warm events occurred to that from cold events during the period 1978-1997, as discussed earlier.

All these studies indicate that due to change in the mean state of the atmosphere, the influence of major climate factors is felt differently in different parts of the globe.

\subsection{Question on Sun NAO Lagged Relationship}

Recent studies (Gray et al. 2013; Scaife et al. 2013; Andrews et al. 2015; Thieblemont et al. 2015) noted solar lagged relationship around places of the north
Atlantic and discussed mechanisms. The current study investigates the robustness of such association. Here, the MLR technique is applied during the same two different time periods as considered in Fig. 5 and solar lagged relationship (lag year 1 to lag year 3, Fig. 6a-c) is performed. The results are also compared with the overall 150 years of data as is done in Gray et al. (2013) and shown in the bottom panel of each figure.

Figure 6a shows results for lag year 1. The top two figures show a clear difference around the north pole which is similar in nature like Fig. 5a respectively, though much weaker. Signature in Fig. 6a, bottom panel, matches to that of the top left panel in places of North Atlantic probably due to longer data records of the earlier period. The result of the bottom panel is similar to that of Gray et al. (2013).

Figure $6 \mathrm{~b}$ and $\mathrm{c}$, are for lag year 2 and 3 respectively. For the North Atlantic region in lag year 2 (Fig. 6b), the bottom panel is dominated by strong signal during the period 1978-1997; whereas, for Fig. 6c, it is overpowered by the earlier period (1856-1977). Strong positive solar signature for 150 years record is around Azores high for lag year 2 and 3 (strongest for lag year 3) which is consistent with the study by Gray et al. (2013). The main findings in Fig. 6, bottom panel (all plots) concerning longer record is in agreement with Gray et al. (2013). The little deviation, if noticed, might be related to a slight difference in the period considered.

The key observation from these analyses is that the lagged relationship is also not robust but sensitive to the period chosen. This analysis supports Sjolte et al. (2018) who discussed that solar NAO link in modelling works is not unequivocally supported by reconstructions. The result of the overall 150 years is mainly dominated by a period that has stronger signals. Hence, caution should be taken in proposing any mechanism based on any detected signal unless that signal is very robust.

There could be arguments about the SLP data qualities which could be poor in polar regions. In methodology, it discussed uncertainty issues and its ranges for SLP data. Moreover, it can also be stated that various popular research (especially, those we compared here e.g., Ineson et al. 2011; van Loon et al. 2007; Gray et al. 2013 etc.) used the same data around polar regions. 


\section{(a) Lag1:}
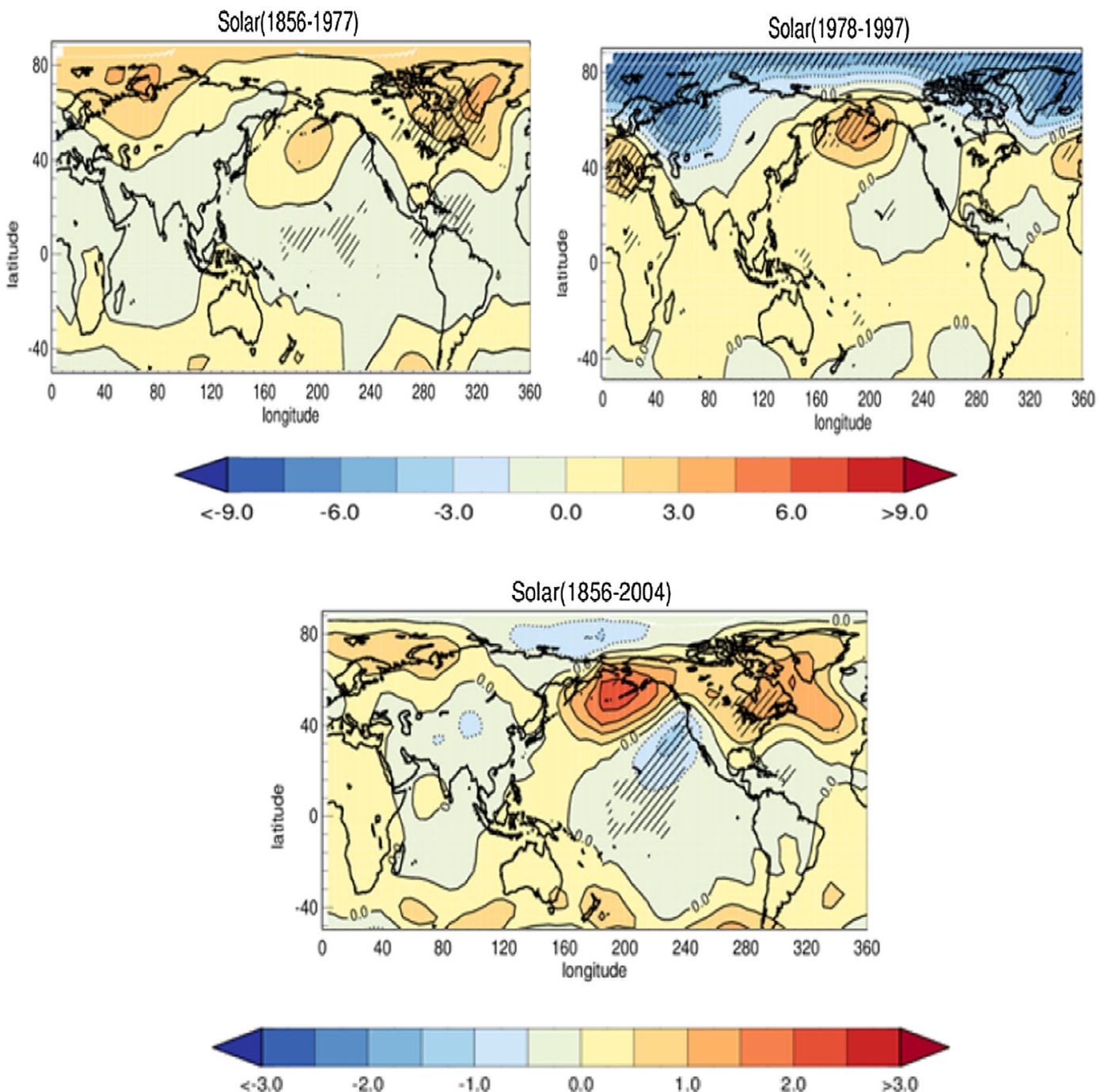

Figure 6

Amplitudes of the components of variability for SLP due to solar cycle variability (max-min), in hPa during DJF for a lag of 1 year, $\mathbf{b}$ lag of 2 years and $\mathbf{c}$ lag of 3 years. Independent factors used are longer term trend, AOD and ENSO. Positive values are shown in brown colour and negative by blue. Shaded regions are estimated significant at the $95 \%$ level using a t-test

\section{Discussion and Summary}

This paper addresses issues to improve understanding of the role of natural factors on surface climate by using observational data and discussing mechanisms. The analyses indicate that caution is required to detect signals relating to natural variability (mainly the Sun) and the robustness of identified signature need to be tested with a critical viewpoint.

A rising trend of global temperature is noticed during periods of 1860-1880, 1917-1944 and 1979-1997 which suggests that the Sun, explosive volcanos and ENSO have roles in regulating global temperature. This shows that it is important to understand their individual as well as combined behaviour. I discussed that SST anomaly around 
(b) Lag 2:
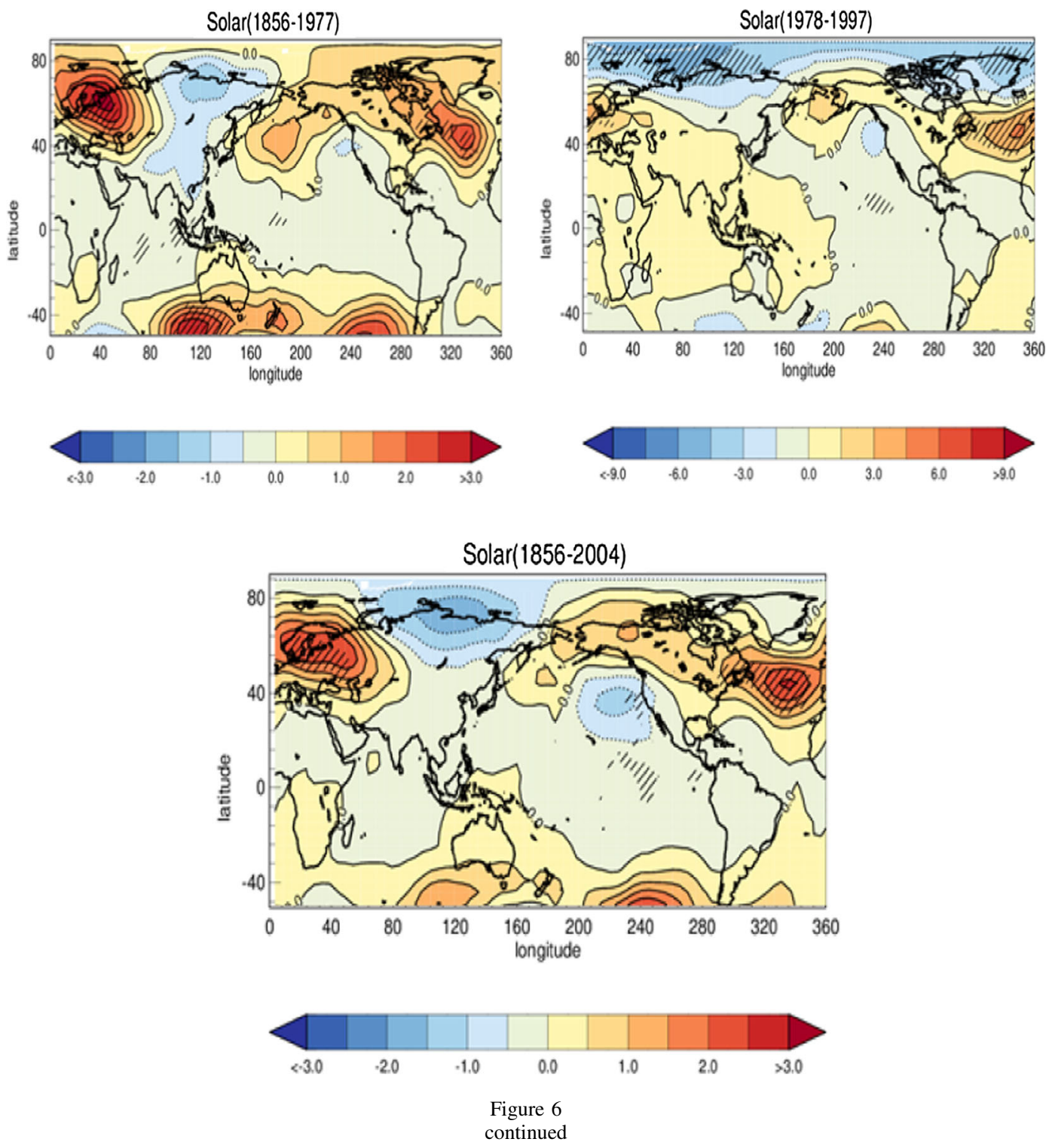

central tropical Pacific and North Atlantic during period 1979-1997 was different compared to other arbitrary base periods. Warming was observed in the central Pacific, though cooling in the north Atlantic. Hence, I focused more on those regions by addressing NAO and ENSO in subsequent analyses.

Winter CET can be explained mainly by the variability of NAO and true irrespective of chosen periods of reference (Table 1, column 1). However,
NAO is influenced by other factors differently at various times (Table 1, column 2).

The last two solar cycles of previous century suggest a strong positive association between the volcanic eruptions and ENSO (Table 1, column 3). Various modelling and observational results also support such connection (Ohba et al. 2013; Adams et al. 2003; McGregor and Timmermann 2011; Stenchikov et al. 2009; Khodri et al. 2017). It 
(c) Lag 3:
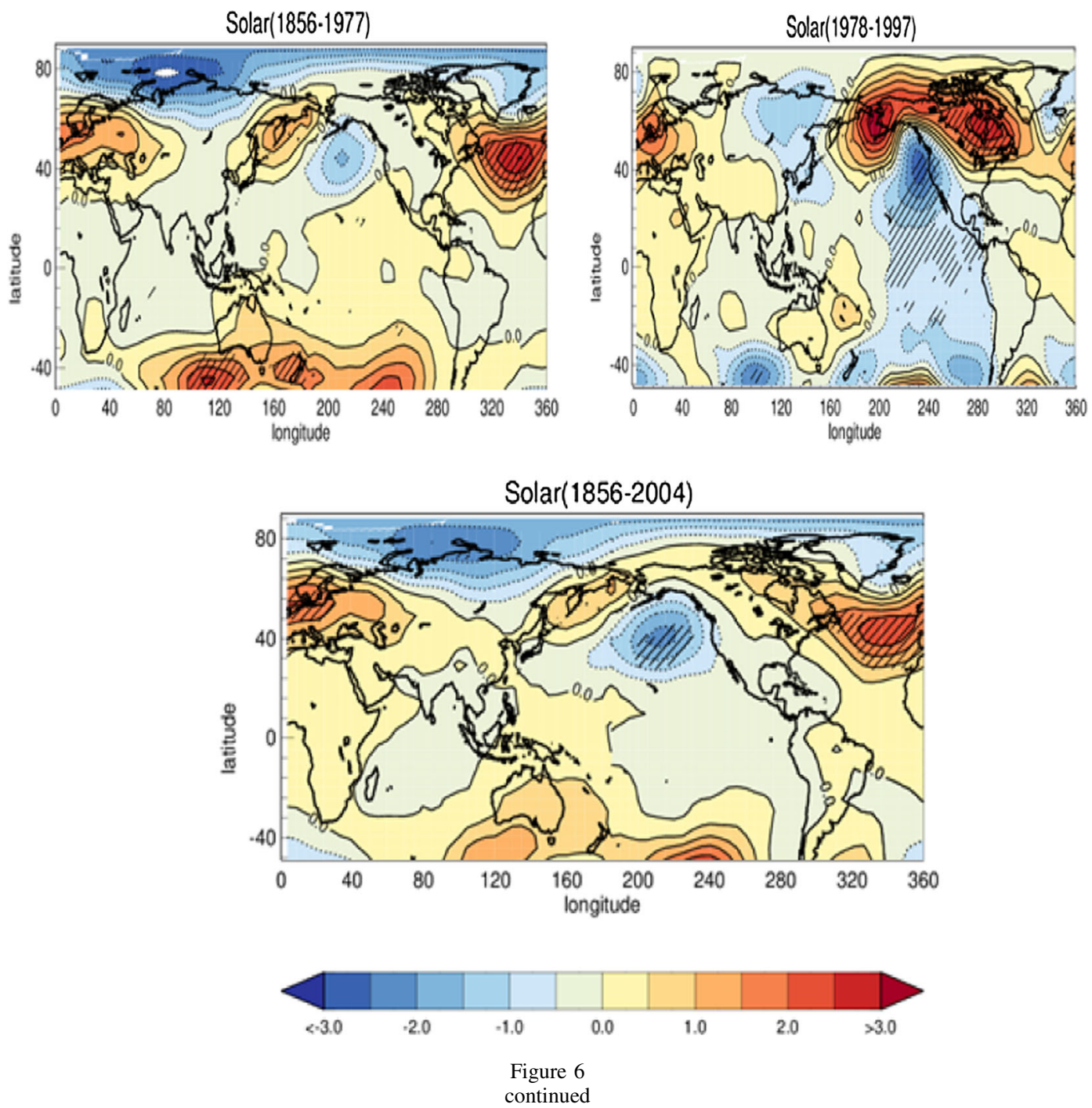

discussed hypothesized mechanisms (Fig. 3b) to explain volcano and ENSO observed connection.

On the other hand, during '1856-1957', a significant negative relationship between the SSN and ENSO is identified during DJF. The signal is positive though insignificant during the second half of the twentieth century (Table 1, column 3). I discussed hypothesized mechanisms (Fig. 3a) to explain cooling (due to active Sun) in the central tropical Pacific during the earlier period.

The results shown here support the fact that shows explosive volcanos are often associated with the positive phase of NAO (Table 1, Period A) and thus agrees with winter north polar warming features (Robock and Mao 1992). Hypothesized mechanisms initiated in the tropical Pacific is mentioned (Fig. 3b). Warming along the central and equatorial Pacific during DJF (warm ENSO due to volcano) could favour a positive phase of NAO, following a nonlinear alignment.

The in-phase relationship between the NAO and the Sun as identified by other studies, though observed during the last two decades of twentieth century, is missing in earlier periods (Table 1, 
column 2 and Fig. 5a). The connection is strongest during later decades (Table 1, period D and Fig. 5a, right) when explosive volcanos coincidentally matched with the active phase of solar cycles. It can also be explained by known mechanisms (Fig. 3b). During later decades, the broader maxima of solar cycles (1-2 year after peak solar years) are inclined to warm events of ENSO (Roy and Haigh 2012; Roy 2014). Such warming via regional Hadley cell is often accompanied by strengthening the midlatitude westerlies and subsequently, may be responsible for positive Sun NAO connection. Following similar mechanism, active Sun and cold ENSO, as it the case for the earlier period, will suggest a weakening of midlatitude westerlies in boreal winter, indicating a negative association between the Sun and NAO (Figs. 3a; 5a, left).

Apart from issues concerning the robustness of earlier proposed connection on the Sun and NAO, the present study also questioned on their known lagged relationship of various scales and shows that solarNAO lagged connection is not unequivocally supported by observational records. Strong volcanos those coincidentally erupted near the peak of active solar cycles can have an impact on the mean state of the atmosphere (both the stratosphere and ocean). Thus, the solar, NAO and ENSO relationship needs to be investigated with additional care.

This work aims at solving and reconciling various contradictory findings. Such critical analysis will be helpful for an improved understanding of various modes of variability and their complicated role on climate. This, in turn, will lead towards a better understanding of complex natural climate variability.

\section{Acknowledgements}

This work was motivated by third-year undergraduate project supervision in the University of Exeter, with project title 'Factors affecting winter temperature around Europe' with codes 'ECM3735'. Figure 2 and Fig. S2 are generated by the NOAA/ESRL Physical Sciences Division, Boulder Colorado from their Web site at https://www.esrl.noaa.gov/psd/. The preprint form of the earlier two versions of this manuscript are also available in the web https://www.preprints.org/ manuscript/201608.0025/v1 (https://doi.org/10.20944/ preprints201608.0025.v1) and https://www.preprints. org/manuscript/201608.0025/v2 (https://doi.org/10. 20944/preprints201608.0025.v2) and included in the reference list.

\section{Funding}

This research did not receive any funding.

\section{Compliance with ethical standards}

Conflict of interest There are no financial and non-financial competing interests.

Open Access This article is licensed under a Creative Commons Attribution 4.0 International License, which permits use, sharing, adaptation, distribution and reproduction in any medium or format, as long as you give appropriate credit to the original author(s) and the source, provide a link to the Creative Commons licence, and indicate if changes were made. The images or other third party material in this article are included in the article's Creative Commons licence, unless indicated otherwise in a credit line to the material. If material is not included in the article's Creative Commons licence and your intended use is not permitted by statutory regulation or exceeds the permitted use, you will need to obtain permission directly from the copyright holder. To view a copy of this licence, visit http://creativecommons.org/licenses/by/4.0/.

Publisher's Note Springer Nature remains neutral with regard to jurisdictional claims in published maps and institutional affiliations.

\section{REFERENCES}

Adams, J. B., Mann, M. E., Ammann, C. M., et al. (2003). Proxy evidence for an El Niño-like response to volcanic forcing. $\mathrm{Na}$ ture. https://doi.org/10.1038/nature02101.

Allan, R., \& Ansell, T. (2006). A new globally complete monthly historical gridded mean sea level pressure dataset (HadSLP2): 1850-2004. Journal of Climate, 19(22), 5816-5842.

Allan, R. J. (2000). ENSO and climate variability in the last 150 years. In H. F. Diaz \& V. Markgraf (Eds.), El Niño and the Southern Oscillation: multiscale variability, global and regional impacts (pp. 3-55). New York: Cambridge Univ. Press.

Andrews, M. B., et al. (2015). A simulated lagged response of the North Atlantic Oscillation to the solar cycle over the period 1960-2009. Environmental Research Letters, 10, 054022.

Baldwin, M. P., \& Dunkerton, T. J. (2001). Stratospheric harbingers of anomalous weather regimes. Science, 294(5542), 581-584. https://doi.org/10.1126/science.1063315. 
Bjerknes, J. (1966). A possible response of the atmospheric Hadley circulation to equatorial anomalies of ocean temperature. Tellus, 18(4), 820-829. https://doi.org/10.1111/j.2153-3490.1966. tb00303.x.

Bond, N. A., Overland, J. E., Spillane, M., \& Stabeno, P. (2003). Recent shifts in the state of the North Pacific. Geophysical Research Letters, 30(23), 2183. https://doi.org/10.1029/ 2003GL018597.

Clement, A. C., Seager, R., Cane, M. A., \& Zebiak, S. E. (1996). An ocean dynamical thermostat. Journal of Climate, 9, 2190-2196. https://doi.org/10.1175/1520-0442.

Compo, G. P., Whitaker, J. S., Sardeshmukh, P. D., Matsui, N., et al. (2011). The twentieth century reanalysis project. Quarterly Journal Royal Meteorological Society, 137(654), 1-28. https:// doi.org/10.1002/qj.776.

Driscoll, S., Bozzo, A., Gray, L. J., Robock, A., et al. (2012). Coupled Model Inter-comparison Project 5 (CMIP5) simulations of climate following volcanic eruptions. Journal of Geophysical Research, 117, D17. https://doi.org/10.1029/2012JD017607.

Emile-Geay, J., Seager, R., Cane, M. A., Cook, E. R., \& Haug, G. H. (2008). Volcanoes and ENSO over the Past Millennium. Journal of Climate, 21, 3134-3148.

Fedorov, A., \& Philander, S. G. (2000). Is El Niño changing? Science, 288(5473), 1997-2002. https://doi.org/10.1126/science. 288.5473.1997.

Gray, L. J., Beer, J., Geller, M., et al. (2010). Solar influences on climate. Reviews of Geophysics, 48, RG4001. https://doi.org/10. 1029/2009RG000282.

Gray, L. J., Scaife, A. A., Mitchell, D. M., et al. (2013). A lagged response to the 11 years solar cycle in observed winter Atlantic/ European weather patterns. Journal of Geophysical Research: Atmospheres, 118, 13405-13420. https://doi.org/10.1002/ 2013JD020062.

Gu, D., \& Philander, S. G. (1997). Inter-decadal climate fluctuations that depend on exchanges between the tropics and extratropics. Science, 275(5301), 805-807.

Haam, E., \& Tung, K. K. (2012). Statistics of Solar Cycle-La Niña connection: Correlation of two auto-correlated time series. Journal of the Atmospheric Sciences, 69, 2934-2939.

Haigh, J. D. (1996). The impact of solar variability on climate. Science, 272(5264), 981-984.

Haigh, J. D., Blackburn, M., \& Day, R. (2005). The response of tropospheric circulation to perturbations in lower-stratospheric temperature. Journal of Climate, 18(17), 3672-3685.

Huang, B., Thorne, P., Smith, T., Liu, W., Lawrimore, J., Banzon, V., et al. (2015). Further exploring and quantifying uncertainties for extended reconstructed sea surface temperature (ERSST) Version 4 (v4). Journal of Climate. https://doi.org/10.1175/JCLID-15-0430.1.

Ineson, S., Scaife, A. A., Knight, J. R., et al. (2011). Solar forcing of winter climate variability in the Northern Hemisphere. Nature Geoscience. https://doi.org/10.1038/NGEO1282.

Ingleby, N. B. (2001). Comments on 'A statistical determination of the random observational errors present in voluntary observing ships' meteorological reports'. Journal of Atmospheric and Oceanic Technology, 18, 1102-1107.

IPCC, Climate Change (2013). The Physical Science Basis. Contribution of Working Group I to the Fifth Assessment Report of the Intergovernmental Panel on Climate Change [Stocker, T.F., D. Qin, G.-K. Plattner, M. Tignor, S.K. Allen, J. Boschung, A. Nauels, Y. Xia, V. Bex and P.M. Midgley (eds.)]. Cambridge
University Press, Cambridge, United Kingdom and New York, NY, USA, $1535 \mathrm{pp}$.

Jones, P. D., Jonsson, T., \& Wheeler, D. (1997). Extension of the North Atlantic Oscillation using early instrumental pressure observations from Gibraltar and southwest Iceland. International Journal of Climatology, 17, 1433-1450.

Kaplan, A., Cane, M. A., Kushnir, Y., Clement, A. C., Blumenthal, M. B., \& Rajagopalan, B. (1998). Analyses of global sea surface temperature 1856-1991. Journal of Geophysical Research C: Oceans, 103(C9), 18567-18589. https://doi.org/10.1029/ 97JC01736.

Kent, E. C., \& Taylor, P. K. (1997). Choice of a Beaufort equivalent scale. Journal of Atmospheric and Oceanic Technology, 14, 228-242.

Kiehl, J. T., \& Trenberth, K. E. (1997). Earth's annual global mean energy budget. Bulletin of the American Meteorological Society, 78(2), 197-208.

Kodera, K., \& Kuroda, Y. (2002). Dynamical response to the solar cycle. Journal of Geophysical Research, 107(D24), 4749. https:// doi.org/10.1029/2002JD002224.

Khodri et al. (2017). Tropical explosive volcanic eruptions can trigger El Niño by cooling tropical Africa. Nature Communications, 8. (Article number: 778).

Laken, et al. (2012). A decade of the moderate resolution imaging spectroradiometer: Is a solar-cloud link detectable. Journal of Climate. https://doi.org/10.1175/JCLI-D-11-00306.1.

Latif, M., Kleeman, R., \& Eckert, C. (1990s). Greenhouse warming, decadal variability, or El Niño? An attempt to understand the anomalous 1990s. Journal of Climate, 10(9), 2221-2239.

Lean, J., \& Rind, D. (2001). Earth's response to a variable Sun. Science, 292(5515), 234-236.

Lenssen, N., Schmidt, G., Hansen, J., Menne, M., Persin, A., Ruedy, R., et al. (2019). Improvements in the uncertainty model in the Goddard Institute for Space Studies Surface Temperature (GISTEMP) analysis. Journal of Geophysical Research: Atmospheres. https://doi.org/10.1029/2018JD029522.

Liu, Z., Vavrus, S., He, F., Wen, N., \& Zhong, Y. (2005). Rethinking tropical ocean response to global warming: The enhanced equatorial warming. Journal of Climate, 18, 4684-4700. https://doi.org/10.1175/JCLI3579.1.

Liu, W., Huang, B., Thorne, P. W., Banzon, V. F., Zhang, H.-M., Freeman, E., et al. (2014). Extended Reconstructed Sea Surface Temperature version 4 (ERSST.v4): Part II. Parametric and structural uncertainty estimations. Journal of Climate, 28, 931-951. https://doi.org/10.1175/JCLI-D-14-00007.1.

Lockwood, M., \& Fröhlich, C. (2007). Recent oppositely directed trends in solar climate forcings and the global mean surface air temperature. Proceedings of the Royal Society A, 463(2086), 2447-2460. https://doi.org/10.1098/rspa.2007.1880.

Manley, G. (1974). Central England Temperatures: Monthly means 1659 to 1973. Quarterly Journal of the Royal Meteorological Society, 100, 389-405.

McGregor, S., \& Timmermann, A. (2011). The effect of explosive tropical volcanism on ENSO. Journal of Climate, 24, 2178-2191. https://doi.org/10.1175/2010JCLI3990.1.

McGregor, S., Timmermann, A., \& Timm, O. (2010). A unifiedproxy for ENSO and PDO variability since 1650. Climate Past, 5, 1-17.

McPhaden, M. J., \& Zhang, D. (2004). Pacific Ocean circulation rebounds. Geophysical Research Letters, 31, L18301. https://doi. org/10.1029/2004GL020727. 
Meehl, G. A., \& Teng, H. (2000s). CMIP5 multi-model hindcasts for the mid-1970s shift and early 2000s hiatus and predictions for 2016-2035. Geophysical Research Letters, 41(5), 1711-1716.

Meehl, G. A., Arblaster, J. M., Branstator, G., \& van Loon, H. (2008). A coupled air-sea response mechanism to solar forcing in the Pacific region. Journal of Climate, 21(12), 2883-2897.

Meehl, G. A., Arblaster, J. M., Matthes, K., Sassi, F., \& van Loon, H. (2009). Amplifying the pacific climate system response to a small 11-year solar cycle forcing. Science, 325, 1114-1118. https://doi.org/10.1126/science.117287.

Miller, J., Cayan, D. R., Barnett, T. P., Graham, N. E., \& Oberhuber, J. M. (1994). The 1976-1977 climate shift of the Pacific Ocean. Oceanography, 7, 1.

Minobe, S. (2000). Spatio-Temporal Structure of the pentadecadal variability over the North Pacific. Progress in Oceanography, 47, 381-408.

Mitchell, D. M., Gray, L. J., \& Charlton-Perez, A. J. (2011). The structure and evolution of the stratospheric vortex in response to natural forcings. Journal of Geophysical Research. https://doi. org/10.1029/2011JD015788.

Morice, C. P., Kennedy, J. J., Rayner, N. A., \& Jones, P. D. (2012). Quantifying uncertainties in global and regional temperature change using an ensemble of observational estimates: The HadCRUT4 dataset. Journal of Geophysical Research, 117, D08101. https://doi.org/10.1029/2011JD017187.

Ohba, M., Shiogama, H., Yokohata, T., \& Watanabe, M. (2013). Impact of strong tropical volcanic eruptions on ENSO simulated in a coupled GCM. American Meteorological Society, 26, 5169-5182. https://doi.org/10.1175/JCLI-D-12-00471.1.

Oliva, et al. (2017). Recent regional climate cooling on the Antarctic Peninsula and associated impacts on the Cryosphere. Science of the Total Environment, 580, 210-223.

Parker, D. E., \& Horton, E. B. (2005). Uncertainties in the Central England Temperature series since 1878 and some changes to the maximum and minimum series. International J. Climatology, 25, 1173-1188.

Parker, D. E., Legg, T. P., \& Folland, C. K. (1992). A new daily Central England Temperature Series, 1772-1991. International Journal of Climatology, 12, 317-342.

Pierce, D. W., Barnett, T. P., \& Latif, M. (2000). Connections between the Pacific Ocean tropics and midlatitudes on decadal timescales. Journal of Climate, 13(6), 1173-1194.

Polvani, L. M., et al. (1990s). The impact of ozone-depleting substances on tropical upwelling, as revealed by the absence of lower-stratospheric cooling since the late 1990s. Journal of Climate, 30, 2523. https://doi.org/10.1175/JCLI-D-16-0532.1.

Qiong, Z., Yue, G., \& Haijun, Y. (2008). ENSO amplitude change in observation and coupled models. Advances in Atmospheric Sciences, 25(3), 361-366.

Robock, A. (2003). Volcanoes: Role in climate. In J. Holton, J. A. Curry, \& J. Pyle (Eds.), Encyclopedia of atmospheric sciences (pp. 2494-2500). London: Academic Press. https://doi.org/10. 1006/rwas.2002.0169. (Invited paper).

Robock, A., \& Mao, J. (1992). Winter warming from large volcanic eruptions. Geophysical Research Letters, 19(24), 2405-2408. https://doi.org/10.1029/92GL02627.

Roy I (2010) Solar signals in Sea Level Pressure and Sea Surface Temperature. Ph.D. Thesis, Department of Space and atmospheric Science, Imperial College London.
Roy, I. (2014). The role of the Sun in atmosphere ocean coupling. International Journal of Climatology, 34(3), 655-677. https:// doi.org/10.1002/joc.3713.

Roy, I. (2016). The role of natural factors on major climate variability in northern winter. Preprints. https://doi.org/10.20944/ preprints201608.0025.v2.

Roy, I. (2018a). Solar cyclic variability can modulate winter Arctic climate. Scientific Reports, Nature Publication, 8, 4864. https:// doi.org/10.1038/s41598-018-22854-0.

Roy, I. (2018b). Addressing on abrupt global warming, warming trend slowdown and related features in recent decades. Frontiers, 6, 136.

Roy, I., \& Haigh, J. D. (2010). Solar cycle signals in sea level pressure and sea surface temperature. Atmospheric Chemistry and Physics, 10(6), 3147-3153.

Roy, I., \& Haigh, J. D. (2012). Solar cycle signals in the pacific and the issue of timings. Journal of Atmospheric Science, 69(4), 1446-1451. https://doi.org/10.1175/JAS-D-11-0277.1.

Roy, I., \& Kriplani, R. (2019). The role of natural factors (Part 1): Addressing on Mechanism of different types of ENSO, related teleconnections and solar influence. Theoretical and Applied Climatology, 137, 469-480. https://doi.org/10.1007/s00704-0182597-z.

Sato, M., Hansen, J. E., McCormick, M. P., \& Pollack, J. B. (1993). Stratospheric aerosol optical depths (1850-1990). Journal of Geophysical Research, 98, 22987-22994.

Scafetta, N. (2013). Discussion on climate oscillations: CMIP5 general circulation models versus a semi-empirical harmonic model based on astronomical cycles. Earth-Science Reviews, 126, 321-357.

Scaife, A., Ineson, S., Knight, J. R., Gray, L., Kodera, K., \& Smith, D. M. (2013). A mechanism for lagged North Atlantic climate response to solar variability. Geophysical Research Letters, 40(2), 434-439.

Sigmond, M., \& Scinocca, J. F. (2010). The influence of basic state on the Northern Hemisphere circulation response to climate change. Journal of Climate, 23, 1434-1446.

Sigmond, M., Scinocca, J. F., \& Kushner, P. J. (2008). Impact of the stratosphere on tropospheric climate change. Geophysical Research Letters, 35, 12. https://doi.org/10.1029/ 2008GL033573.

Sjolte, et al. (2018). Solar and volcanic forcing of North Atlantic climate inferred from a process-based reconstruction. Climate of the Past, 14(8), 1179-1194. https://doi.org/10.5194/cp-14-11792018.

Sobel, A. H., Held, I. M., \& Bretherton, C. S. (2002). The ENSO Signal in Tropical Tropospheric Temperature. J. Climate, 15, 2702-2706.

Stenchikov, G., Delworth, T. L., Ramaswamy, V., Stouffer, R. J., Wittenberg, A., \& Zeng, F. (2009). Volcanic signals in oceans. Journal of Geophysical Research, 114, D16104. https://doi.org/ 10.1029/2008JD011673.

Thieblemont, R., et al. (2015). Solar forcing synchronizes decadal North Atlantic climate variability. Nature Communications, 6, 8268.

Thompson, D. W. J., Baldwin, M. P., \& Wallace, J. M. (2002). Stratospheric connection to northern hemisphere wintertime weather: Implications for prediction. Journal of Climate, 15(12), 1421-1428. 
Toniazzo, T., \& Scaife, A. A. (2006). The influence of ENSO on winter North Atlantic climate. Geophysical Research Letters, 33, L24704. https://doi.org/10.1029/2006GL027881.

Trenberth, K. E., \& Hoar, T. J. (1996). The 1990-1995 El NiñoSouthern Oscillation Event: Longest on record. Geophysical Research Letters, 23, 57-60.

Trenberth, K. E., \& Hoar, T. J. (1997). El Niño and climate change. Geophysical Research Letters, 24(23), 3057-3060.

van Loon, H., Meehl, G. A., \& Shea, D. J. (2007). Coupled air-sea response to solar forcing in the Pacific region during northern winter. Journal of Geophysical Research: Atmospheres, 112, D02108. https://doi.org/10.1029/2006JD00 7378.

Vecchi, G. A., \& Soden, B. J. (2007). Global warming and the weakening of the tropical circulation. Journal of Climate, 20, 4316-4340.

Visbeck, M. H., Hurrell, J. W., Polvani, L., \& Cullen, H. M. (2001). The North Atlantic Oscillation: Past, present, and future.
Proceedings of the National Academy of Sciences, 98(23), 12876-12877. https://doi.org/10.1073/pnas.231391598.

Wang, C., \& Fiedler, P. C. (2006). ENSO variability and the eastern tropical Pacific: A review. Progress in Oceanography, 69, 239-266.

Wang, T., Ottera, O. H., Gao, Y., \& Wang, H. (2012). The response of the north Pacific decadal variability to strong tropical volcanic eruptions. Climate Dynamics, 39(12), 2917-2936.

White, W. B., Lean, J., Cayan, D. R., et al. (1997). Response of global upper ocean temperature to changing solar irradiance. Journal of Geophysical Research: Oceans, 102(2), 3255-3266.

Zhang, D., \& McPhaden, M. J. (2006). Decadal variability of the shallow Pacific meridional overturning circulation: Relation to tropical sea surface temperatures in observations and climate change models. Ocean Modelling, 15(3-4), 250-273.

Zhang, Q., Guan, Y., \& Yang, H. (2008). ENSO amplitude change in observation and coupled models. Advances in Atmospheric Sciences, 25(3), 361-366.

(Received August 26, 2019, revised May 18, 2020, accepted May 21, 2020, Published online June 8, 2020) 